Columbia Law School

Scholarship Archive

\title{
Policing, Crime and Legitimacy in New York and Los Angeles: The Social and Political Contexts of Two Historic Crime Declines
}

Jeffrey Fagan

Columbia Law School, jfagan@law.columbia.edu

John MacDonald

JMACDONA@RHSMITH.UMD.EDU

Follow this and additional works at: https://scholarship.law.columbia.edu/faculty_scholarship

Part of the Criminal Law Commons, Law and Society Commons, and the Law Enforcement and Corrections Commons

\section{Recommended Citation}

Jeffrey Fagan \& John MacDonald, Policing, Crime and Legitimacy in New York and Los Angeles: The Social and Political Contexts of Two Historic Crime Declines, Columbia Public LaW ReSEARCh PaPer No. 12-315 (2012).

Available at: https://scholarship.law.columbia.edu/faculty_scholarship/1761

This Working Paper is brought to you for free and open access by the Faculty Publications at Scholarship Archive. It has been accepted for inclusion in Faculty Scholarship by an authorized administrator of Scholarship Archive. For more information, please contact scholarshiparchive@law.columbia.edu. 


\title{
Columbia Law School
}

Public Law \& Legal Theory Working Paper Group

Paper Number 12-315

Policing, Crime and Legitimacy in New York and Los Angeles: The Social and Political Contexts of Two Historic Crime Declines

\author{
Jeffrey Fagan \\ Columbia Law School \\ John MacDonald \\ University of Pennsylvania
}

August 21, 2012 


\title{
Policing, Crime and Legitimacy in New York and Los Angeles: The Social and Political Contexts of Two Historic Crime Declines
}

\author{
Jeffrey Fagan* \\ John MacDonald $^{+}$ \\ Columbia University \\ University of Pennsylvania
}

The relationship between citizens and police occupies a central place both in urban politics and in the political economy of cities. In this respect, for nearly 50 years, New York and Los Angeles have been bellwethers for many of the nation's larger cities. In each city, as in cities across the world, citizens look to police to protect them from crime, maintain social order, respond to a variety of extra-legal community concerns, and reinforce the moral order of the law by apprehending offenders and helping bring them to justice (Reiss, 1971; Black, 1980; Skogan and Frydl, 2004). Beyond enforcing social and political order, the police are the front line representatives of a variety of social service needs in communities (Walker, 1992). Accordingly, policing is an amenity of urban places that shapes how citizens regard their neighborhood and their city, and in turn, the extent to which citizens see their local institutions as responsive and reliable (Skogan, 2006). Effective and sustainable governance, especially when it comes to public safety, depends on the capacity of the institutions of criminal justice to provide "value" that leverages legitimacy and cooperation among its citizens (Moore et al., 2002; Skogan and Frydl, 2004; Tyler and Fagan, 2008; Tyler, 2010).

How the police exercise their legal authority is an aspect to policing that is particularly salient in larger urban areas and often competes with performancebased evaluations of police. How the police exercise their legal authority has fundamental implications for public sentiments about the quality of police services and trust in political institutions more generally (Moore et al., 2002; Tyler and Fagan, 2008). There is an expressive function in the way that police exercise their authority that signals their regard for the dignity and rights of citizens (Smith, 2008). These signs of respect leverage the cooperation of citizens with police, and engage citizens as partners in the co-production of security (Fagan and Meares, 2008). When these expressions are absent, though, trouble follows when citizens depend on the police for their safety and at the same time harbor resentments over their omnipresence in their lives.

For nearly five decades, tension between citizens and police in Los Angeles (LA) and New York (NYC) have pervaded relations and fouled the

\footnotetext{
* Isidor and Seville Sulzbacher Professor of Law, Columbia University; Professor of Epidemiology, Mailman School of Public Health, Columbia University

${ }^{+}$Associate Professor, Department of Criminology, University of Pennsylvania
} 
polity. Throughout this time, the institutions of policing occupied a special place in the political and social cultures of each city, for at least four reasons. First, LA and NYC each suffered a crime epidemic from the late 1960s to the early 1990s that is visible in each city's homicide and robbery trends. We discuss these trends later in this chapter. These epidemics placed unprecedented demands on the police and each city's political institutions, and created recurring conflicts between police and the most crime-ridden and heavily policed minority communities. The mix of crime, race and policing placed intense political pressures on the police. ${ }^{1}$

Next, a series of police scandals and crises focused unwelcome attention on the police, threatening to undermine their perceived legitimacy and corrode citizen confidence in the police as effective agents of crime control. Third, the scandals of the police were also confounded with racial politics of cities, as a number of high profile police-abuse of force cases deepened historical minority distrust of the police in both LA and New York. Both the scandals and patterns of civil rights violations by their police landed each city in federal court and resulted in legal interventions that attempted - and we show later, largely failed - to reshape the institutions of policing.

Fourth, in response more to different forms of corruption scandals than racial upheavals or conflicts, police in both LA and NYC both underwent significant institutional transformations in their policing architectures. The tipping point in this transformation in each city was the intervention and administrative reforms brought about by (twice) former commissioner William J. Bratton. At the outset, these reforms fundamentally changed the strategies and tactics of policing. In both cities crime rates dropped significantly after these reforms, lending credence to the argument that the police have a material impact in influencing crime rates (Kelling and Cole, 1996; Bratton and Kelling, 1998).

These seeming "victories" over crime changed the discourse on the politics of the police in LA and NYC from one of scandal and reforms to control corruption to managing the conflicts between aggressive police tactics and disparities in their application towards minorities (Alpert et al., 2006; Ayres and Borowsky, 2008; Gelman, Fagan, and Kiss, 2007; Ridgeway, 2007; Fagan et al., 2010). Nevertheless, policing in each city in the last decade was colored and shadowed by the attention of the federal courts who responded to investigate, assess, and monitor both police agencies response to controlling crime and maintaining civil rights. ${ }^{2}$ Beyond the acute periods of crime decline, as each city transitioned to a low(er) crime era, the two cities took sharply divergent paths both in police-citizen relations and policing tactics. Litigation bore very different kinds of fruit in each city, and the current atmosphere in the two cities reflects sharply divergent institutional postures toward crime and community (Compare Stone et al.'s 2009 report on LA to Fagan et al. 2010's report on NYC). Those divergent paths form the core of this chapter, and forecast very different futures for policing in the two cities. 


\section{This Chapter}

In this chapter, we tell the story of policing, crime and the search for legitimacy over the past two decades in LA and NYC. Throughout this complex political, normative and legal landscape, crime rates dropped dramatically in each city to levels not seen the early 1960s. Accordingly, a full understanding of the natural history of crime and policing in each city has to start at a much earlier point in time, for two reasons. First, criminologists tend to forget history, especially history that predates the sharp rise in crime that began in the U.S. in the mid-1960s, and the nationwide decline starting in 1993. There is a tendency in the criminology literature to decouple periods of rising crime from periods of falling crime, without viewing the two movements as a single social and historical context. $^{3}$

So, to understand the present, we look to the period before the crime rates began a steep rise in each place, at the moment when the smoldering tensions between citizens - especially racial and ethnic minorities - and the police exploded into open conflict. One part of this chapter, then, is a modest effort to construct a "history of the present" to explain how two cities took different but intertwined paths from low to high crime and back again. ${ }^{4}$

Second, crime itself has undergone historic transformations, both in its substance and its trends. While crime in each city has shown patterns typical of recurring and closely spaced epidemics, the longer view shows that its rise and fall over five decades seems to reflect an historic step and transformation that itself may have defied the best efforts of police, police reformers, courts to effect short-term change. Rather, the trends over a longer interval seem to point to profound political, economic, and structural transformations in the two cities into eras of relative safety and calm. The chapter itself illustrates the tension between historic shifts and the situational, and the importance of having a zoom lens to detect both the micro-landscape of small steps within a larger historical process, as well as the larger social and political ecology of changing cities.

In the chapter, then, we move back and forth between the shorter lens of interactions between citizens and police, to the longer focus of crime trends over time and the political economy of the two cities. An exclusively narrow focus on social exchanges and interactions between citizens and police would complicate efforts to find connections between cities as historically and socially distant as $\mathrm{NY}$ and LA may seem. But from the broader perspective of police as part of the urban social fabric of cities, we identify several threads that connect the past and future of policing in the nation's two largest cities. These threads are far more complex and work at a larger scale than the everyday drama of crime and justice. The factors that shape large shifts in crime must be seen as working on a scale that is comparable to these shifts. How these factors have developed in this 
decade will give us a window through which to envision crime and justice in the decade to come.

The chapter tells this story in four sections. We begin with a discussion of the evolution of policing in the two cities, assessing reciprocal and dynamic changes that reflected both the crises of crime epidemics and crises within the police. Next, we examine the role of litigation on the evolution of policing. Policing regimes in each city were challenged in federal courts, as well as by elected officials in local investigations. The outcomes of litigation in the two cities were starkly different, a reflection in part of the structure of the litigation itself as well as the posture of each city toward the links between scandal and reform. While Los Angeles linked a major policing scandal with reform, the NYPD compartmentalized the origins of its scandal to specific forms of police corruption and use of force, while ignoring the need to regulate the constitutional parameters of routine police-citizen interactions. The legacies of litigation in each city are quite different, with important lessons for the future.

Third, we examine the historic transformations in crime itself. Criminologists, as we noted, tend to take a shorter view of crime trends that expand for one or perhaps two decades. Shorter-term crime trends are important in their social, political and personal consequences. But short-term boom-or-bust explanations provide limited perspective for the longer historical trends that we observe for each of the two cities. Crime rates today in both New York and Los Angeles have returned to the same levels as 50 years ago, before the upheavals in policing in the midst of that cycle, eras that spanned significant changes in the social and political order of the cities. By stepping back, we show that what may be meaningful and consequential in the short-term may be less important when contextualized from longer and larger historical processes.

In the fourth section, we broaden our focus to examine basic changes in the structures of the cities, looking closely at factors that were implicated in the boom-and-bust cycles of crime that characterize the past half century. We locate crime trends in these larger structural transformations of the cities, and contextualize policing in what seems to be an historic and evolutionary cycle. We conclude with a brief look at the past and the future. We envision, at least for the near future, very different paths in the evolution of policing in LA and NYC and its place in these transformed cities.

\section{Policing in the City}

We begin the story of the rise and fall of crime in LA and NYC by focusing on the police. There are several reasons to start here, and postpone a discussion of the larger social structural and ecological changes that were taking place at the same time in each city. The most salient is both the recurring political and social science attention to the relationship between police and crime, which 
we visit in a later section. A second is the sheer magnetism of the policing story in each city that leads us to start at what we see as its modern origins. We begin with an overview of the historical arc that frames the institutional reforms in policing in this modern era. We begin with the riots of the 1960s and their legacy. We then move to the institutional dynamics of police tensions and reforms, and into the modern era of the "new policing" in each city.

\section{The Legacies of the Riots}

The scars of riots in NYC and LA, events that took place nearly 50 years ago, were part of the historical process that shook the police departments in each city, and perhaps intensified the 50 year cycle of crime and its decline that followed.

By 1967, riots erupted in more than 250 both large and small cities across the country (Kerner Commission Report, 1968). The 1965 Watts riot in LA received closer scholarly and popular attention than the riots in Harlem in NYC a year earlier (Cohen and Murphy, 1966; Perlestein, 2008). Nevertheless, the two events had much in common. In each case, tensions between Black citizens and police became the flashpoint that ignited sustained violence and property damage. In each case, also, the riots marked the opening of a breach of trust between minority citizens and the police that lasted for decades.

Harlem, in northern Manhattan, was the scene of one of the nation's first riots. The riot erupted in July, 1964, when police shot and killed a 15 year old African American teenager following a dispute with a local White building superintendent. When a police officer intervened, the teenager attacked him with a knife and was shot by the officer. Riots followed shortly in neighborhoods across the city, often as a sequence of events beginning with protest marches that ignited into violence when police attempted to control the marches (Walker, 2012).

Within days, the Harlem riots spread across to other cities the country, including several cities with multiple episodes of riots. More than 325 riots in 257 cities broke out between 1964 and 1968 (Eisenhower Commission, 1969). There were 150 riots in 1967 alone (Kerner Commission, 1968). Even cities where police believed they had good relationships with the minority community were susceptible to race riots, demonstrating that police departments may not have had a clear picture of how they were perceived in these communities.

For police in NYC, the Harlem riots were a turning point not only in their relationships to the minority communities, but in the stance of the city and its political leadership toward crime and the underlying social conditions. While the U.S. Supreme Court had, at the outset of the 1960s sought to curb the police tactics that led to many of the riots, the Harlem riots exposed fractures in the Court's dual campaign of improving police procedure and supporting civil rights 
in the 1960s (Stuntz, 2010). The election of liberal mayor John Lindsay in 1965 represented the face of social reform in response to the riots, while the battle over civilian oversight of the police brought forward a quite different face that sought deregulation of the police and a pullback from the procedural reforms earlier in the decade (Perlestein, 2008).

The spark for the 1965 riots in the Watts section of LA illustrates this triggering mechanism. Marquette Frye, a 21 year old African-American was pulled over for running a red light by a California Highway Patrol officer. Mr. Frye had been allegedly been drinking alcohol and could not produce a driver's license. It was a hot night, and many people were outside to witness the event, including, eventually, Mr. Frye's mother. An altercation began between Mr. Frye, his mother and the police and ended with Mr. Frye, his brother and his mother under arrest. The crowd became rowdier when the LA police (LAPD) arrived in response to a the highway patrol officers distress call, and more general violence in the Watts ghetto broke out as the crowd "stoned passing automobiles, assaulted white motorists, and threatened a police command post." The tensions from this event tipped off a six-day urban riot that spread throughout LA (Obserschall, 1965). The Watts riot resulted in 3,927 arrests, more than 1,000 injuries, 600 buildings damaged and 34 deaths. ${ }^{5}$

Governor Pat Brown appointed a commission of six whites and two African-Americans to prepare "an objective and dispassionate study" of the Watts Riots. The commission interviewed 79 witnesses and questioned around 10,000 people about the events. On December 2, 1965, three months after the commission began, it produced its report, "Violence in the City - and End of a Beginning?" The report was short, only 88 pages, and the description of the riots was only about 15 pages.

"Violence in the City", also known as the McCone Commission report, presented what might be read as the "Riffraff Theory" of the Watts Riots. Police Chief Parker was blamed by many South LA residents for exacerbating tensions with the African American community by disregarding widespread claims of police abuse - including claims of excessive force and routine use of abusive language. Parker himself was widely quoted publicly denouncing rioters as "monkeys in the zoo" (Oberschall, 1965; p. 324). Yet the McCone exculpated Whites, including the police, from blame, focusing instead on "social, economic and psychological conditions" that faced rioters, but still placed blame on the Watts residents. The commission found that (1) less than 3 percent of the ghetto population participated in the riots; (2) that rioters were "riffraff" meaning unemployed, young, criminals and outsiders; and (3) that the majority of the Black population opposed the riots.

The McCone Commission and Chief Parker weren't alone in hurling racial invective at the rioters. Future California governor Ronald Regan referred to the rioters as "law-breakers and mad dogs," and Parker insisted that the riots were the 
work of "a gang of Negro Hoodlums" (Cohen and Murphy, 1968; Perlestein, 2008) and "monkeys in the zoo" (Obserschall, 1965). LA Mayor Yorty insisted that a small portion of the ghetto community had instigated the riots and had expertise in areas such as making Molotov Cocktails, a fact that was rejected by the McCone Commission.

The national reaction to the riots was quite different. The Kerner Commission, as it was named after its chairman, delivered a report starkly in contrast to the McCone commission. The riots that produced a nationwide disturbance in 1967 created a space in which to challenge the riffraff theory that was advanced by the McCone Commission (1965). The Kerner Report saw the violence as criminal, but also as response to oppression, and something that could only be cured by a change in the actions of White America.

The riots were the product both of increasing crime and disorder in inner cities and increasing tension and conflict between citizens and police in those same neighborhoods. Surveys in that era showed that "nonwhites were more apprehensive than whites" (Weiner and Wolfgang, 1989) They had reason to be, as the number of index crimes in the cities ("homicide, forcible rape, aggravated assault, robbery, burglary, grand larceny and auto theft") in proportion to the population, was nearly three times higher than in the surrounding suburbs. Most of the victims of crimes were other city residents, meaning that nonwhites were far more likely, in some instances $78 \%$ more likely, to be the victims of crimes.

The scars of the riots remain visible today -50 years later - in two ways. First, the scars are painfully visible in the physical landscape of a few stubbornly poor cities, as well as those where poverty and crime have abated. In both gentrifying Harlem and chronically poor Newark, vacant lots and abandoned buildings or factories are visceral physical reminders of the struggles of that era. But the scars also remain visible in a philosophy and jurisprudence of criminal law that has instantiated the disparate fates of racial minorities in the criminal justice system. A sign of the legacy of the close connection between race, police and riots could be seen in the police posture toward rioters in the Rodney King riots in Los Angeles that erupted in 1992. There, the police were known to use the term NHI - "No Humans Involved" - when issuing radio calls to patrolling officers who were being sent to homes in Black sections of the city (Christopher Commission, 1998).

\section{Scandals}

The riots of the 1960s and the recurring crime epidemics through the 1990s show the complexity of the policing task in American cities over the past 50 years. In LA and NYC, persistent high crime rates contributed to stressors on the forces that led to both systemic pathologies in the form of racial conflict and corruption scandals, and then unprecedented large scale institutional reforms to 
policing. We detail the paths of institutional reform and its predicates in each city, with important lessons about both the intersections of these stories and the divergent paths that followed reform and transformation.

\section{Los Angeles}

The history of corruption within the LAPD ranks during the first half of the $20^{\text {th }}$ century lead the organization under police Chief William H. Parker and his successors to separate itself from the political establishment. The LAPD was managed from 1950 - 1966 by Chief Parker, who - despite the Watts riots - was celebrated within the police profession for innovation in civil service protections of officers and command staff, professional development and training, and vice enforcement. ${ }^{6}$ Parker's innovations came after a previous half century of repeated corruption scandals and frequent turnover of police chiefs. ${ }^{7}$

While the McCone Commission report offers very little in the way of direct criticism of the LAPD, the report does note the problems between the LAPD and the African American community. It suggested the need to "place greater emphasis on their responsibilities for crime prevention as an essential element of the law enforcement task, and that they institute improved means for handling citizen complaints and community relationships" (McCone, 1965; part 5). In particular, the report offers suggestions for revamping the citizen complaint process to increase the transparency of the system and prevent conflict of interests, where police commanders were required to review complaints against their own subordinate officers (see Abu-Lughod, 2007).

The LAPD through the history of police chiefs Parker, Davis, and Gates was focused on professional police administration and not known for its community relations. It also became politically insulated from both democratic regulation and administrative accountability. The Los Angeles City Council, at the urging of Chief Parker, enacted an appointment process for its chief of police that guaranteed virtual lifetime tenure (Greene, 1998). These three chiefs moved toward a strong centralized command and control that emphasized full enforcement of the law and limited officer discretion. The eclipse of political control and external accountability over the LAPD insulated it and fostered its own cultural norms (Christopher Commission, 1991; Greene, 1998) where police legitimacy strictly an administrative rather than a normative matter. Partnership with the community was simply not a paramount in this design of police professionalism.

At the same time, communities in South LA near Watts were still very much attuned to the legacy of the Watts riots of 1965. Full and formal enforcement of the law was not what residents of South LA neighborhoods had in mind for police reform when they complained in 1965 about police abuse, entrenched poverty, inadequate access to housing and schools, and crime. Despite the structural problems noted in the McCone Commission report, concentrated 
poverty, racial segregation, and poor police-community relations remained endemic of LA through the 1970s and 1980s. Formal, militarized policing embraced by Chief Gates in zones that are best portrayed as "poverty traps" (Bowles, Durlauf and Huff, 2006) was a prescription for tensions and a breach in trust between minority citizens and the police.

It was in this context of 25 years of a politically isolated police force and a social and economically isolated and impoverished minority community that two scandals emerged within a decade. Both shook the LAPD from its closed posture and launched the processes of reform.

On March 3, 1991 an African American resident named Rodney King attempted to evade a traffic stop by the LAPD. His arrest and beating were caught on videotape and "went viral" long before there was You Tube, much less a widely accessible internet. ${ }^{8}$ The subsequent acquittal of LAPD police officers charged with the beating of King sparked the 1992 LA urban riots. Like the August 1965 Watts riots, police abuse of authority (Christopher Commission, 1991) was again the touchstone event that triggered massive riots that spread from LA to other cities. The fact that the King incident lead to such violent protests was indicative of the deep tensions that existed in South LA neighborhoods, and in particular the poor relations with the African American community. ${ }^{9}$

Mayor Tom Bradley appointed a commission headed by Warren Christopher to investigate the King beating and the riots; its 1991 report provided the catalyst for change in the LAPD. The Commission found the LAPD had created a "crime fighter" and "warrior" culture among its officers that rewarded high arrest rates and overwhelming force when civilians resisted arrest. The department rejected the moves to community policing that had become an important innovation in policing elsewhere in the nation (Christopher Commission, 1991).

In June 1992, LA City Council followed the Christopher Commission's recommendations and replaced Daryl Gates with former Philadelphia Police Commissioner Willie L. Williams, who was the first African American police chief of LA. ${ }^{10}$ Two years later, the LAPD issued a strategic plan, "Commitment to Action," which called for partnerships between the police, community and other branches of local government. The plan involved a revamping of the Basic Car Strategy, which set up a defined neighborhood area for a dedicated patrol car all under the guide of one of eighteen LAPD defined community police divisions (defined by police with community input), and increased training of senior and new recruits on community and problem solving policing strategies (Glenn et al., 2003). ${ }^{11}$ These were the first halting steps by the LAPD toward a community policing model. Figure 1 shows an example of the Rampart Community Police Division and corresponding basic car areas. The Rampart police division, as we discuss later, becomes an important part of the story of scandal and reform. 
Figure 1.

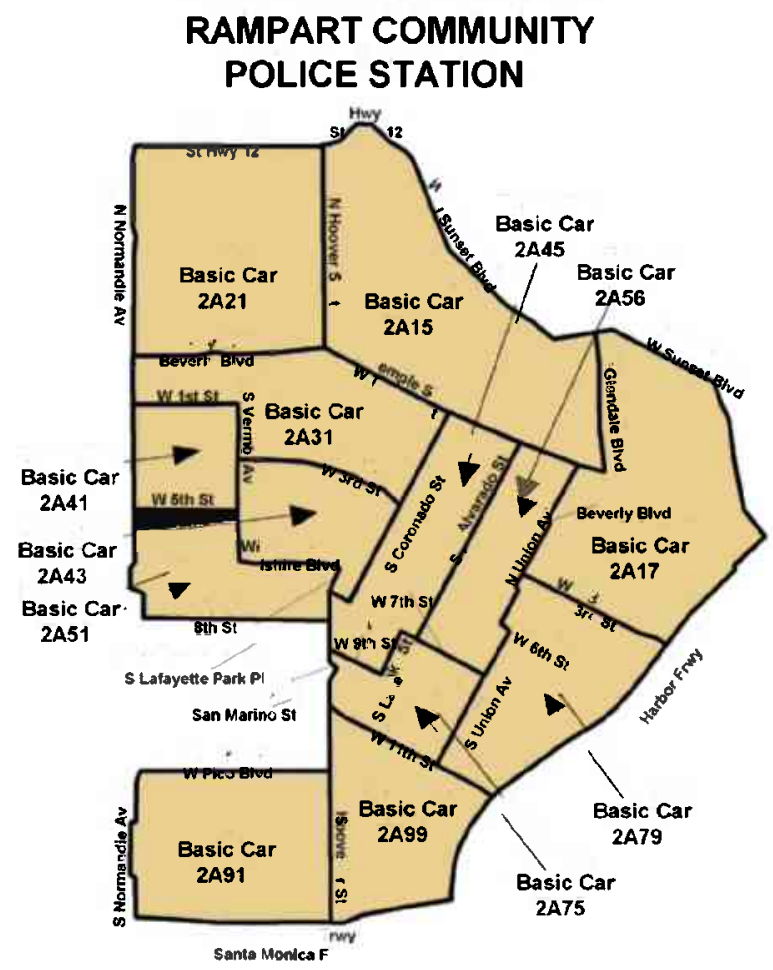

Still, there was intense resistance to community policing within the LAPD middle and upper management ranks (Glenn et al., 2003), eventually costing Williams his job. He was replaced in August 1997 by Deputy Chief Bernard C. Parks, the city's second African American chief. Parks, even while attempting to build community ties, focused his efforts on tactical units to combat crime. In the next section, when we examine crime trends in Los Angeles, we will show that crime dropped significantly under Chief Williams, and rose again under Chief Parks.

It was on Parks' watch that the Rampart scandal was uncovered, the second deep scandal in the LAPD within a decade. On September 21, 1999, Parks formed a board of inquiry (BOI) of LAPD command staff to examine the depth of the alleged corruption in the Rampart police division and the celebrated CRASH (Community Resources Against Street Hoodlums) program. The BOI report focused almost exclusively on the problem of a few corrupt officers and not the systemic problems within the LAPD (Board of Inquiry into the Rampart Corruption Incident, Public Report, 2000). ${ }^{12}$ A subsequent report commissioned by the LA Police Commission criticized the LAPD for its failure to address larger 
problems in the department's internal culture that rewarded the ends-justify-themeans approach to crime fighting (Report of the Independent Review Panel, 2000). The fallout of the LA Police Commission review panel was apparent. By 2005 the California court's overturned 100 falsely obtained convictions, 20 officers were removed or left duty, and just over $\$ 70$ million was paid in civil settlements as a result of this corruption scandal. ${ }^{13}$

The Rampart scandal set the stage for the two measures that have led to major changes in the internal operation of the LAPD and its relationship to the community: federal civil rights litigation that produced nine years of federal oversight under a Consent Decree negotiated with the U.S. Department of Justice, and the hiring of Commissioner William Bratton to oversee the transformation of the LAPD. Those stories are told in the sections that follow.

\section{New York}

One of the legacies of the riots in NYC was the ascension of a new class of political leaders from the city's African American and Latino communities. Adam Clayton Powell, Jr. was elected to Congress representing Harlem in 1960, and immediately raised issues of civil rights, including police misconduct, both on the floor of the House and also in Harlem and across the city's minority neighborhoods. Powell was especially hard on the NYPD, accusing police in Harlem of corruption that included providing protection to drug sellers in return for lucrative payoffs. Powell had some history to draw on, including a scandal involving a gambler, Harry Gross, who made payoffs regularly to every precinct in Brooklyn (English, 2011). The Gross scandal led to hundreds of arrests and convictions. The trail of payoffs eventually led to City Hall and forced the resignation of Mayor William O'Dwyer.

Powell's accusations, which he made in 1960, even before the riots, presaged the corruption scandal of 1964 involving the NYPD's elite 48-person "Watchdog" group. The most volatile scandal was dramatized by the revelations of Detective Frank Serpico, and became public news in 1971. His disclosures of pandemic corruption and cover-ups led to the appointment of the Knapp Commission in 1970. The antecedents of this scandal lie in the ashes of the 1960s, and could be traced to three narratives. First, in the wake of the riots, a heroin epidemic spread through the NYC's minority neighborhoods (Preble and Casey, 1969). Drug distribution organizations profited heavily, as did secondary markets in prostitution, gambling and fencing goods stolen by addicts. These networks depended on police protection. Testimony before the Knapp Commission revealed how, fueled by the new economics of heroin distribution, the residual system of low-level routine payoffs and minor acts of corruption among police suddenly became big business, reaching from the lowest ranks of patrol officers through the detective branches, and into some corners of the command ranks (Knapp Commission Report, 1972). ${ }^{14}$ 
Second, the late 1960s was a period of political violence in NYC. Both in NYC and elsewhere, revolutionary groups including the Black Panther Party, the Weather Underground, and smaller groups all engaged in either shootings of police officers or conspiracies to bomb public places. Although the ambitions of these groups outstripped their impacts, they were seen by NYPD officers as an imminent threat to their lives. In addition to a conspiracy indictment against the Panthers, the shooting of a police officer at a Harlem Mosque in 1972 set off sparks of conflict not only between the police and the Nation of Islam community in Harlem, but between the police union, police commanders and city leaders over blame for the officers' death. Blame was at first placed on then Lieutenant Benjamin Ward, who a decade later went on to become the City's first African American police commissioner. The conflicts with community and the external threats against police officers shielded public attention from the spreading knowledge of corruption in the NYPD.

The third narrative was the political hangover from the battle over civilian review of the NYPD. In 1966, Mayor John Lindsay created a Civilian Complaint Review Board (CCRB) to address citizen grievances against police for excessive force, false arrest, and other forms of police misconduct. The move came at a time of racial polarization in NYC over citizen control of schools, a conflict that played out both publicly and bitterly in the predominantly African American Brownsville neighborhood in Brooklyn. The police union, the Patrolman's Benevolent Association, pledged to empty its treasury to defeat Lindsay's creation (Perlestein, 2008). After a 1966 riot in Brownsville, site of the school conflict, the PBA qualified a referendum on the November ballot to dissolve the CCRB. The CCRB was defeated in a 55-40 landslide.

One of the sites of the scandals that led to the Knapp Commission Report was the $30^{\text {th }}$ Precinct in Harlem, which 30 years later became site of another NYPD drug corruption scandal, known as the "Dirty 30." The Knapp Commission was formed in 1970 to investigate police corruption, based in no small part on Serpico's 1971 whistle-blowing testimony and that of fellow-officer Sergeant David Durk. The Commission, officially known as the Commission to Investigate Alleged Police Corruption, in fact didn't begin its hearings until after Serpico's revelations to the Commission's investigators. The commission produced criminal indictments against corrupt police officials and officers, and led to the replacement of Commissioner Howard Leary (a Lindsay appointee) with Commissioner Patrick V. Murphy. Murphy was tasked to clean up the department rather than redesign its strategies and tactics. Murphy implemented proactive integrity checks, oversaw massive transfers of senior personnel, implemented mandatory job rotation in key areas, and provided funds to pay informants. He also went after citizens who were complicit in attempts to bribe police officers.

Within two decades, a second corruption scandal erupted, with the drug trade again central to the narrative. Again, the Mayor, David Dinkins, appointed 
former judge Milton Mollen in July 1992 to head The City of New York Commission to Investigate Allegations of Police Corruption and the AntiCorruption Procedures of the Police Department, popularly referred to as the Mollen Commission. The Mollen Commission was tasked to investigate "the nature and extent of corruption in the Department; evaluate the departments procedures for preventing and detecting that corruption; and recommend changes and improvements to those procedures" (Mollen Commission Report, 1994). Mollen carefully drew lines to distinguish the corruption patterns uncovered by the Knapp Commission from the corruption of the Mollen era. Corruption during the Knapp investigation was systemic: a pattern of monetary exchanges between criminals and police, with an unspoken agreement to conceal other forms of police misconduct including brutality and other constitutional violations. In other words, Knapp revealed a culture and practice where criminals and police officers gave and took bribes, and bought and sold protection. Corruption was, essentially, consensual.

Mollen's investigation revealed patterns, deeply ingrained in the police culture, of brutality, theft, abuse of authority and active police criminality (Mollen Commission, 1994). The commission report described a nexus between corruption and brutality, which essentially doubled down on the Knapp-era scandals. One testifying officer, Michael Dowd, discussed the deep place of this nexus in the culture of the NYPD. "[Brutality] is a form of acceptance. It's not just simply giving a beating. It's [sic] the other officers beginto accept you more" (Mollen Commission, 1994). Officer Dowd and others described hundreds of acts of brutality they had engaged in; yet apparently no fellow officer had filed a complaint about either one of them. Officers primarily from the 30th, 9th, 46th, 75th and 73rd precincts were caught selling drugs and beating suspects. ${ }^{15}$ The Dirty 30 scandal resulted in nearly one hundred convictions against seventy defendants being thrown out due to police perjury (Human Rights Watch, n.d.). With approximately fifteen lawsuits still pending, the city has already paid $\$ 2$ million in civil settlements to perjury victims (David Kocieniewski, "Man framed by police officers wins payments," New York Times, February 12, 1998).

The scandal bled into the regime of the next police commissioner, William Bratton, who was appointed in 1994, shortly before the Mollen Commission report was published. In his efforts to reform the department, Bratton stated that if officers behaved properly, he would back them absolutely, but if they used unnecessary force, "all bets are off" (New York Times, 1994). Yet, when a civilian deputy commissioner in charge of internal affairs pushed for the creation of a special anti-brutality unit that would be available twenty-four hours a day to investigate allegations promptly, he was forced out of the department in 1995 (Kraus, 1995; Human Rights Watch, n.d.). Although most of the reforms recommended by the Mollen Commission -- improvements in recruiting, scrutiny during probation, integrity training, and improved supervision - were implemented by 1998 (Herbert, 1998), the tensions from as far back as the 1960s and the struggle for police oversight were a constant in the culture of the NYPD. 
The PBA continued to oppose Bratton's stricter disciplinary measures, and the Mollen Commission's call for changes in the police union's response to allegations of corruption. Indeed, litigation surrounding the Abner Louima assault by NYPD officers in 1997, ${ }^{16}$ implicated the police union in the cover-up of that infamous incident.

\section{Reform}

The common thread in the stories of police reform in LA and NYC is not just the presence of William Bratton, but the critical role of scandal as a launching pad for reform. In LA, Commissioner Bratton used the platform of scandal and an external commission to achieve reforms both in accountability of individual officers, while internally pursuing the types of strategic and tactical reforms that have been influential across the country. In NYC, Bratton also benefited from a scandal - the Dirty 30 - that created a political space in which he could implement both management and tactical reforms in the political slipstream of the Mollen Commission's findings without the external constraint of litigation. And, in a similar pattern, Bratton used both scandal and litigation as a rationale for departmental reform in LA, where he relied both on his own instincts and the reform insights gained in NYC.

The Rampart scandal, the review, and subsequent consent decree set the stage for a new era of management reform in LAPD. On October 2002 William J. Bratton was appointed as LAPD's police chief. Bratton having served as Chief of NYPD and instituting its COMPSTAT program brought a similar management philosophy to the LAPD. From 1996 to his appointment as LAPD chief of police Bratton had worked in the private sector, including serving as a consultant for Kroll Associates monitoring team oversaw the implementation of the Federal Consent Decree with the LAPD. ${ }^{17}$

Bratton's primary focus was on implementing steps of the consent decree and instituting COMPSTAT within the LAPD command staff. His management philosophy was to use COMPSTAT to make strategic decisions about officer deployment and to set police division benchmarks for crime reductions. In contrast to previous efforts to reduce crime, this new LAPD approach did not rely exclusively on specialized units and tactical responses. Instead, each division captain was going to be responsible for crime trends and formulating a response in his or her police area. The LAPD instituted this approach under the title of COMPSTAT Plus and directed by George Gascon, LAPD Assistant Chief of Police and Director of Operations.

In contrast to the NYPD COMPSTAT model where performance was benchmarked in monthly command staff meetings, COMPSTAT Plus involved detailed inspections of underperforming police divisions. For police divisions that were underperforming Gascon assigned an audit team of LAPD commanders who would inspect the current patrol, investigation, analysis, and management 
and supervision of these areas. After a thorough review was conducted the audit team would work with the police division to develop its own strategic plan to meet the crime reduction goals. ${ }^{18}$ It is notable that this approach to policing was a sea change in LAPD. Never before had the approach to reducing crime focused on a community-wide approach that relied primarily on line-officers and command staff. Gone was the sole focus on tactical units that had been the staple LAPD approach dating back to the Parker administration. The model of COMPSTAT Plus, however, was based on police accountability to the crime rates and not improving community sentiment. Although one can reasonably argue that the LAPD was mindful that reducing crime could in turn improve public sentiment, even in the African American community, community policing was not a central player in the department's organizational change. Interestingly, the LAPD continued to direct its field services through its community policing plan, and the use of the Basic Car remained part of the LAPD organization, but the actual benchmarks of the organization were not strictly on communityrelationship building.

Like NYC, LA witnessed a significant reduction in crime rates after the implementation of Bratton's COMPSTAT approach. But in contrast to the NYPD model, the COMPSTAT Plus approach did not result in the rapid reallocation of line officers to impact zones or the deployment of aggressive stop and frisk polices. While research on motor vehicle stops conducted as part of the consent decree found numerous geographic disparities in the rates of motor vehicle stops, these disparities cannot be tied the movement of police personnel in response to strategic crime reduction goals (Alpert et al., 2006; Ayres and Borowsky, 2008). By the time Bratton resigned as police chief in October, 2009 he oversaw a sixyear consecutive decline in crime, the lifting of the Federal Consent Decree, and no major corruption scandals. At present it is unclear whether his replacement LAPD Chief Charlie Beck will continue to focus resources on the COMPSTAT model or develop other strategies. It is notable that Charlie Beck was appointed, in part, because of his reputation for community collaboration, including overseeing relationships with the business improvement districts and non-profit services groups in MacArthur Park, located in the Rampart Division, and Downtown LA. ${ }^{19}$

\section{Litigation}

In each city, litigation formed the legacy of the crime declines and the scandals of the1990s. It also was a background drama in the consolidation of crime declines through the following decades. Litigation was an essential intervention that complemented the internal management reforms of Chief Bratton, and was part of the fabric of policing during most of his tenure in LA. In NYC, the threat of litigation was raised in 1999 by an investigation by the New

York State Attorney General Litigation of alleged civil rights violations, including racial profiling, by the NYPD. Litigation was a constant in the political and 
policing environment since 2001, but with seemingly little effect (Fagan et al., 2010). The case studies of each city show the stark differences in the responses to litigation by each city and its police, and raise important questions about what litigation can achieve as an intervention in police reform.

\section{Los Angeles}

The next phase of attempted LAPD reform came through outside intervention. On November 2000 the city of LA entered into a consent decree with the U.S. Department of Justice to oversee the operations of the LAPD, in part responding to the specific Rampart scandal as well as a concern with widespread police abuse of authority violating constitutional guarantees of citizens under the $4^{\text {th }}$ and $14^{\text {th }}$ amendments. This five-year term of the consent decree dedicated a large share of oversight to the review of procedures of management and supervision of officers to promote civil rights integrity as well as the conduct of general police activity, including the use of stop, search, and arrest powers. Included in the consent were specific provisions that indicated "LAPD officers may not use race, color, ethnicity, or national origin (to any extent or degree) in conducting stops or detentions, or activities following stops or detentions, except when engaging in appropriate suspect-specific activity to identify a particular person or group." (Consent Decree, p. 40). And, the consent decree also required that LAPD officers to complete an "electronic report each time an officer conducts a motor vehicle stop" (Consent Decree, p. 40).

The Consent Decree was helpful to Commissioner Bratton in his program of reform, both internally and externally. Many of the requirements of the Consent Decree worked reciprocally but in parallel to the strategic, tactical and cultural innovations that he pursued. Whether the litigation was successful, however, was sharply contested. An analysis of the reforms of the LAPD under the Consent Decree was sought by the Los Angeles Police Foundation, an independent organization that supports the activities of the LAPD (Stone et al., 2009). The report found that the LAPD was in substantial compliance with the terms of the Consent Decree, and was a factor in the decision by the U.S. District Court Gary A. Fress to terminate the consent decree in July 2009. In his order, Judge Fress noted that: "When the Decree was entered, LAPD was a troubled department whose reputation had been severely damaged by a series of crises..... In 2008, as noted by the Monitor, 'LAPD has become the national and international policing standard for activities that range from audits to handling of the mentally ill to many aspects of training to risk assessment of police officers and more."

The conditions cited in the report that suggest substantial reform are in fact a curious mixture of increases in policing coupled with reports of citizen approval of police effectiveness in the heavily policed African American and Hispanic communities. The report describes a declining rate of use of force at the same time that both pedestrian and motor vehicle stops doubled over the seven 
years of the consent decree. Arrests rose in the period of the consent decree, as did arrests per stop, while prosecutorial declinations declined (Stone et al., 2009). These increases were seen as successes, despite the general view that arrest should be a last resort when policing crime and disorder, a notion endorsed in the "Broken Windows" framework (Wilson and Kelling, 1982) that informed the NYPD reforms under Commissioner Bratton (Bratton and Knobler, 1998; Maple and Mitchell, 1999). The increased police activity was seen as a positive sign that litigation didn't inevitably lead to a withdrawal from policing, or de-policing, by officers fearing increased departmental oversight and scrutiny.

Two other indicia suggest that the reforms left substantial room for improvement. According to the Stone et al. (2009) report, more than two-thirds of Hispanic and African American residents rated the LAPD as doing a "good" or "excellent" job at controlling crime and calling offenders to account. But other indicia suggest that a substantial minority within each of these groups was dissatisfied with the LAPD. One in ten African American residents reported that almost "none" of the LAPD officers they encounter treat them and their friends and families with "courtesy or respect". The other indicia that suggests a more moderate impact of the Consent Decree is the persistence of racial disparities in police-citizen contacts.

It is surprising that approval of the LAPD is so strong given the demography of police-citizen contacts in Los Angeles (Ayres and Borowsky, 2008) and the increase in the incidence of both non-arrest and arrest contacts between citizens and police. Analyzing stop data from 2004, the only year made available to them, Ayres and Borowsky (2008) reported statistically significant higher rates of police stops, searches, citations, and arrests of African American and Hispanic persons compared to Whites, even after controlling for location differences in the city. They also report that "hit rates" from stops, frisks and searches were significantly lower for non-whites compared to white suspects. Ayres and Borowsky (2008) reject a claim that these rates reflect higher rates of criminality among minority citizens, citing the lower rates of seizure of weapons, drugs or other contraband, or arrests on outstanding warrants.

The two pictures of the consent decree mirror the experiences of other cities that were placed under federal court supervision through court-appointed monitors (Schwartz, 2010; Fagan and Geller, 2010). One reason for the gap in these narratives about the consent decrees is the difference in emphasis on which factors matter to which communities. To a court, or perhaps to a public seeking a more accountable and professional police regime, the reforms in the inner workings of the department were good news. But to those who sought relief from policing excesses or constitutional violations in decisions on whom to stop and search for suspicious behaviors, the failure to curtail racial disparities suggests that the excesses of the pre-litigation era remain unabated. Accountability, then, has two different faces - internal accountability for professionalism and good management, and external reforms for accountable and performance-based 
policing. One might reasonably ask whether the achieved reforms, however welcomed and needed they may be, are the right reforms when the racial disparities in police conduct that motivated the litigation remain persistent realities of policing.

\section{New York}

The cycles of scandal - both large and small - and reform that have burdened the NYPD for nearly 50 years led to litigation against the City of New York and the NYPD in the late 1990s. And since that time, class action litigation (as opposed to individual civil actions) has multiplied to the present day. Two incidents in particular motivated first an investigation of the NYPD by the New York State Attorney General, and then litigation based on the investigation reports. One was the 1997 assault on Abner Louima in a NYPD precinct station, and the other was the killing of an uarmed citizen, Amadou Diallo, by officers who were part of an elite Street Crime Unit that conducted aggressive stops and searches in the hunt for guns. The SCU was formed early in the Bratton police administration in New York, and was expanded following Commissioner Bratton's resignation in 1996. The cascade of these two scandals animated both the NYS AG investigation as well as the litigation that followed.

The Spitzer Report, as the AG investigation was known, cited evidence that the NYPD engaged in racially biased police practices in the conduct of decisions on whom to stop and frisk (Spitzer, 1999; Gelman, Fagan and Kiss, 2007). About one stop in six lacked a clearly articulated justification on forms filled out by the NYPD, and nearly one in four lacked sufficient documentation to render a judgment of its constitutionality. The racial disproportionality was stark: Black New Yorkers were nearly three times as likely to be stopped relative to their crime rate as were White New Yorkers; the comparable rate for Hispanics was about half the disparity for Blacks. While there has been some debate about the causes of these disparities (Ridgeway, 2007), no one can deny that Blacks and Hispanics were feeling the brunt of the NYPD's stop and frisk tactics and that these disparities are not a simple artifact of differences in crime rates between areas that different groups inhabit.

The Center for Constitutional Rights filed a lawsuit, Kelvin Daniels v City of New York, in 2001, relying on the Spitzer report as evidence, coupled with the testimony of a class of plaintiffs. The litigation was settled in an agreement in December 2003 that - unlike the Los Angeles consent decree - did not include court oversight. NYC promised to reduce racial disparities in police stops, to improve documentation, and to reject racial profiling as a basis for conducting street stops. Training on constitutional requirements for street stops and other reforms designed to increase constitutional compliance also were designed. Assorted other reforms were promised, including the conduct of citizen forums and community surveys. Documentation of street stops, thought to be spotty at 
best by the Spitzer investigation, was integrated into the COMPSTAT system of crime accounting.

Daniels was, however, a failure. There was no internal report comparable to the Stone et al. (2009) assessment of the LAPD to determine whether there were significant or effective institutional reforms that resulted from Daniels. Even so, lawyers for the Daniels plaintiffs reported that there was little compliance with the terms of the settlement. And, there was an exponential growth in street stops during the interval of the Daniels settlement. Fagan et al. (2010) showed that stops increased 600\% between 1998, the year preceding the Spitzer Report, and 2006, a year before the December 2007 expiration of the Daniels Consent Decree. Almost all of the increase during that time was in districts that were predominantly populated by African Americans. Fagan et al. (2010) observed that the increases were present even after controlling for racespecific crime rates in each police precinct. Similar patterns, though smaller in magnitude but still statistically significant, were found for areas with concentrations of Hispanic residents. The "yield" from these stops was low about one gun seized for every thousand stops, and arrests in about one stop in 20 . Figure 2 shows the growth in racial disparity throughout this period. While the NYPD claims that the growth in stops has kept crime rates low (Smith \& Purtell, 2007), Figure 2 suggests that in fact, crime rates were declining since long before the run-up in stops, and have in fact been declining in NYC since 1991 (Zimring, 2011).

Daniels failed for four reasons. First, there was the absence of any external oversight or enforcement of reforms. Essentially, the NYPD and the City promised to reform, but faced no incentive to do so in a timely fashion. Second, the NYPD firmly believed that these tactics were essential in keeping the crime rate low and to maintain its slow decline through the decade following the appointment of Raymond Kelly as Police Commissioner. Third, there was public support to continue these tactics. ${ }^{21}$ The support was equivocal in the minority communities, where stops were most heavily concentrated, and was strong in predominantly White sectors of NYC. Accordingly, there was no sense of urgency among community or political leaders to hold the NYPD accountable for compliance with the terms of the settlement that largely impacted minority communities. Perhaps most important was the timing of the litigation: Daniels was filed in 2001, before the 9/11 terror attacks, and shortly afterward, the Police Commissioner Bernard Kerik - in his final year in office - very publicly renounced racial profiling. And within a few months, the 9/11 attacks generated widespread support if not admiration for the NYPD. In that climate, there was no political will or even attention to the issues raised by Daniels and the state Attorney General Spitzer before that.

But the most significant reason for the failure of Daniels was the structure of the stipulated settlement agreement. The terms did not include an external or court-appointed monitor, a departure from other consent decrees or collaborative 
agreements negotiated around the same time, including the Los Angeles Consent Decree. There were no stated performance benchmarks to assess changes in racial disparities in stops and frisks. There was no requirement for public release of data. Rather, the NYPD were required to produce reports to plaintiffs and later, to the City Council, a requirement they ignored until the shooting death of Sean Bell in November 2006, a year before the scheduled expiration of the Daniels settlement, in a botched undercover operation. There were no requirements for evaluation of training or other personnel management systems. There was no external auditing of the data and the routine reports on the bases for citizen stops consistent with Fourth Amendment requirements. When violations were detected, as in the case of the $600 \%$ increase in stops from 2003-2006 that exacerbated racial disparities (Fagan et al., 2010), there was no enforcement mechanism for readdressing these practices. The NYC settlement agreement stands in sharp contrasts to the consent decree in Los Angeles that required active monitoring of racial disparities in stop, arrests, and use of force behaviors by the LAPD. One can only imagine what reforms and changes in transparency might have occurred if the NYPD had been subject to similar oversight.

Figure 2: Terry Stops and Felony Crimes per 100,000 Persons, New York City, 1998-2009

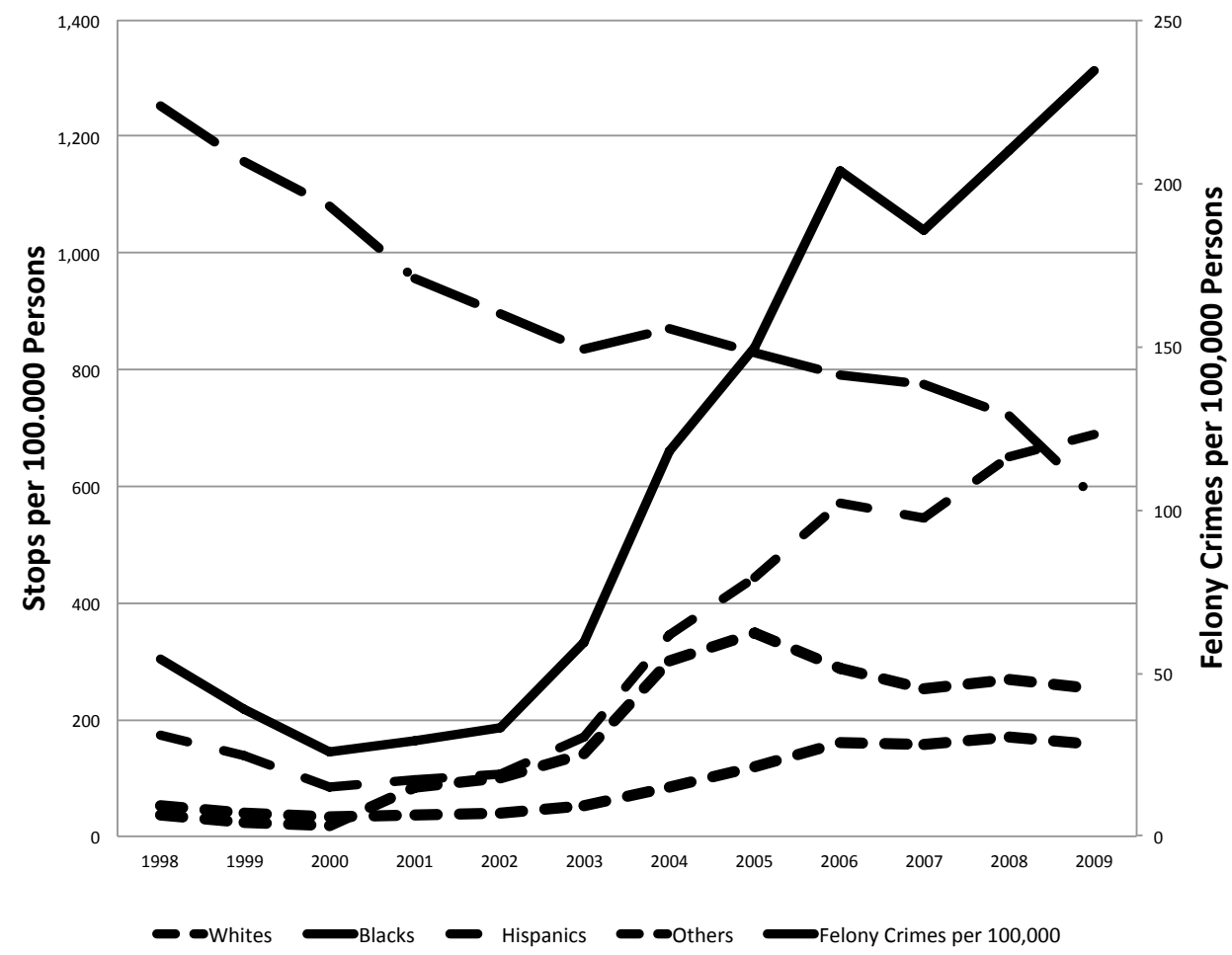

Source: New York City Police Department, Various Years; Fagan et al., 2010; Uniform Crime Reports, various years

The growing disparities led to a second lawsuit, filed immediately upon the expiration of the Daniels settlement, by the same civil rights organization that 
had filed Daniels: the Center for Constitutional Rights. The litigation continues through this writing with the case Floyd et al. v. City of New York. ${ }^{22}$ In addition, two other lawsuits have been filed, Davis et al. $v$ City of New York in 2010, and Ligon et al. $v$ City of New York in 2012. Each alleges both racial discrimination and Fourth Amendment (search and seizure) violations in the conduct of police operations in the apartment buildings that characterize much of the City's housing stock. Plaintiffs in Davis allege discrimination in the conduct of stops and the enforcement of trespass laws in public housing complexes. Plaintiffs in Ligon allege similar claims in the enforcement of these laws in privately owned buildings. In each case, the litigation cites abuses under the NYPD's Operation Clean Halls program, where officers conduct patrols in the lobbies and stairwells of privately-owned buildings - with the consent of the landlords - searching for persons who are illegally in the buildings. ${ }^{23}$ The City says these tactics are essential to eliminating longstanding problems of drug dealing and related violence in these buildings. But residents are mixed on these tactics, and the plaintiffs complain not only of illegal searches, but of often being arrested in their own buildings that they are legally allowed to be in.

The persistence of litigation in NYC suggests both the animating power of scandal to provoke litigation, but also the limitations of political regulation and accountability in policing in the post-Mollen era. It's not just class action litigation that characterizes this climate, but private litigation as well: according to the City Comptroller, New York City has paid out over $\$ 570$ million in settlements of individual private law suits in the past decade (Liu, 2011).

Litigation in NYC, and the disagreements over the impacts of the litigation in LA, suggests a further and difficult question: whether the aggressive and proactive policing tactics that characterize both cities inevitably will lead to racial conflict and litigation. Perhaps the absence of meaningful regulation of the police in NYC, dating back at least 50 years, creates a political climate where accountability and lawfulness is secondary both to the norms of the police culture and the demands for security at all costs. The scandals dating back to the 1960s and before suggest that this is not simply a matter of high crime eras, for as we show below, that era ended both in NYC and LA a decade ago. Rather, the persistence of litigation and the allegations that these lawsuits seek to address, may suggest a more disturbing notion of the endogeneity of such norms in the modern policing institution when unabated by outside intervention. LA, as we suggest in our epilogue on The Future for policing in each city, seems to be on a very different path. In NYC, the bitter war over these three lawsuits suggests a dark vision of a permanent divide between the minority citizens of the City and the institutions that exist to protect them

\section{Crime and Policing}

The connection between the crime reductions in NY and LA since 1990, at the height of the crack epidemic in each city, with the cycles of scandal and 
reform is not a simple calculation. While notable reforms in policing occurred in each city following urban unrest, corruption scandals, internal reforms, and new models of policing, it remains unclear how much these cascading dramas shaped the crime trends we observe in each city. In this section we analyze the changes in crime rates between 1960 and 2010 in the two cities, using the broader historical lens that captures the eras of unrest, rising crime, scandal and reform. We focus on only robbery and homicide rates because these crimes are less likely to be influenced by changes in police reporting practices over this time period. Homicide in particular has not changed by definition. And, there are reasons to expect that the police generally do not under report homicides. ${ }^{24}$

\section{The 50 Year Arc}

The trends over the 50 year period in robbery and homicide rates in the two cities are very similar in both timing and the shape of both increase and decline. Both cities experienced a massive increase in crime between the mid 1960s and the early 1980s, despite different trajectories in internal governance and reforms. In LA, the various efforts of the professional model of law enforcement under police chiefs Parker, Davis, and Gates had little discernable effect on crime, as measured by robbery or homicide rates through the 1980s. Crime rates also rose in NYC under several police commissioners through the same eras. The crime increase in NYC and LA mirrored the crime increase seen in the majority of large US cities across this period (UCR, various years), suggesting that large secular processes were animating crime trends through forces that were beyond the control of local police in any single city.

\section{Bad Things Come in Threes}

From the 1960s through the early 1990s, violent crime increased in three waves, each one closely tied to an epidemic of drugs - heroin in the late 1960s, cocaine and the emergence of street drug markets in the late 1970s, and crack cocaine and the rapid expansion of retail drug selling predominantly in American inner cities (Johnson et al., 1990). In each city, starting in the mid-1980s, the increase was best described as an epidemic of violence, especially among adolescents and young adults ages 13-24, (Cook and Laub, 1998). The coupling of the temporal phasing of crime in each city with concurrent drug epidemics has been the source of theoretical speculation and empirical analyses (Blumstein, 1995; Fagan 1990, 1992). In these renderings of the causes of a violence epidemic, the connection was through drug selling in open-air markets (Zimmer, 1984; Goldstein 1985, 1989; Fagan, 1990) and the proliferation of high caliber firearms (Blumstein and Wallman, 2000). In each city, drug selling organizations animated forms of group violence that were tied to the economic instrumentality. In Los Angeles, these groups emerged from, and sometimes coincided with, the rise of street gangs in the late 1970s. In New York, drug selling organizations dominated territories and markets (Fagan, 1990, 1994; Johnson et al., 1990). 
Drugs were hardly the only crime correlate that was co-morbidly tied to the three-stage run-up in crime. By the mid-1970s, guns became the majority instrumentality in homicide (Zimring and Hawkins, 1997). We can't know whether the proliferation of gun homicides was the result of excess gun manufacture and faulty marketing controls that put guns into the hands of young offenders (Hemenway, 2004) or a byproduct of the rapid expansion of inherently violent street drug markets (Johnson et al., 1990; Fagan, 1992) in each city. But the fact remains that nearly all of the increase and all of the decline in homicides across the 50 year window was due to changes in gun-related deaths (Fagan, Zimring and Kim, 1998; Cook and Laub, 2002; Zimring, 2006, 2011; Hemenway, 2007).

\section{The Crime Declines}

Figures 3 and 4 shows the trends for homicide rates and robbery rates between 1960 and 2010 for NY and LA, and begins the discussion of the crime declines. In these figures, we placed lines marking years where major police issues occurred, including the 1965 Watts riots, the 1991 Safe Streets Act of NY, the 1992 Los Angeles riots, the 1994 advent of COMPSTAT in NY and the LAPD community policing plan, and the 2002 COMPSTAT + program launched by LAPD police chief William Bratton.

The similarity in the patterns of increase and decline are remarkable. The rates rose and declined in both cities in the same decades, despite public perception that the cities are distinct from each other on both crime and its correlates. Again, the shared pattern of increase and decline speaks to the effect of more general secular trends that influence cities across the U.S. Various police reforms and innovations occurred between the 1960s and late 1980s, but there is little evidence of any influence on the homicide rate.

The trends show with clarity that policing crises and reforms are | correlated with general secular trends. When we examine any year as a point of departure from the decade specific trends in homicide and robbery for both cities it suggests that a police reform contributed to a lower rate of crime. Still, the effects of reforms are best viewed as nested in the longer 50-year secular trends in these and other major cities (Rosenfeld, Fornango, and Baumer, 2006; Harcourt and Ludwig, 2006). Crime rates began declining in each city in 1992, despite starkly different political, social and policing environments. In other words, the shared onset and shape of the decline could suggest that policing had little effect. So, for example, we could attribute the decline in Los Angeles to the Rodney King riots, the appointment of Chief Williams in 1992 to lead the LAPD, the work of the Christopher Commission in revealing systemic problems in the LAPD and in the communities most heavily policed, or to Chief Williams' community policing plan that began in 1994 (and that was fiercely resisted by the patrol force). In $\mathrm{NYC}$, we could claim that the onset of the crime decline began with police reform resulting from the 1991 Safe Streets Act, the implementation of 
COMPSTAT initiatives and other policy reforms in 1994, or the work of the Mollen Commission that investigated police corruption beginning in 1993. In other words, no matter what the political landscape or the specific local crime conditions, a secular decline in crime began in the two cities at almost exactly the same time, and by the year 1993, this trend was seen in cities across the nation (Blumstein and Wallman, 2000).

Figure 3. Homicide Rates per 100,000 Persons, New York and Los Angeles, 1960-2010

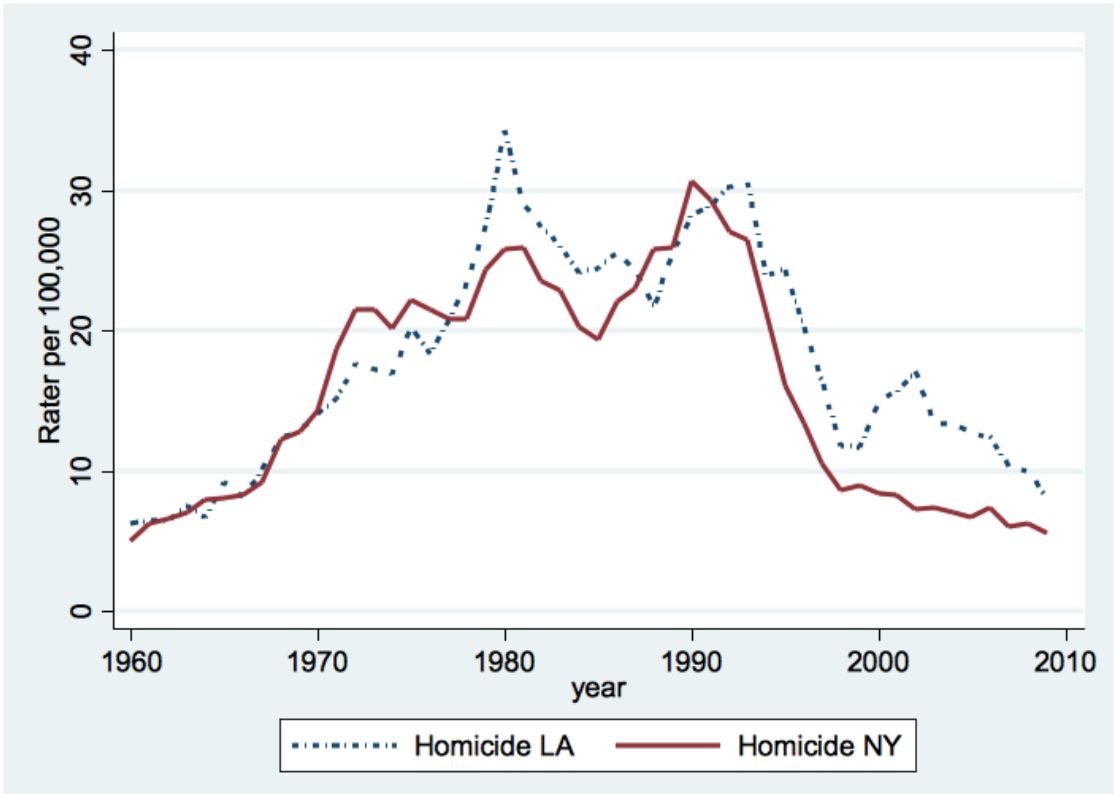

Figure 4. Robbery Rates per 100,000 Persons, New York and Los Angeles, $1960-2010$

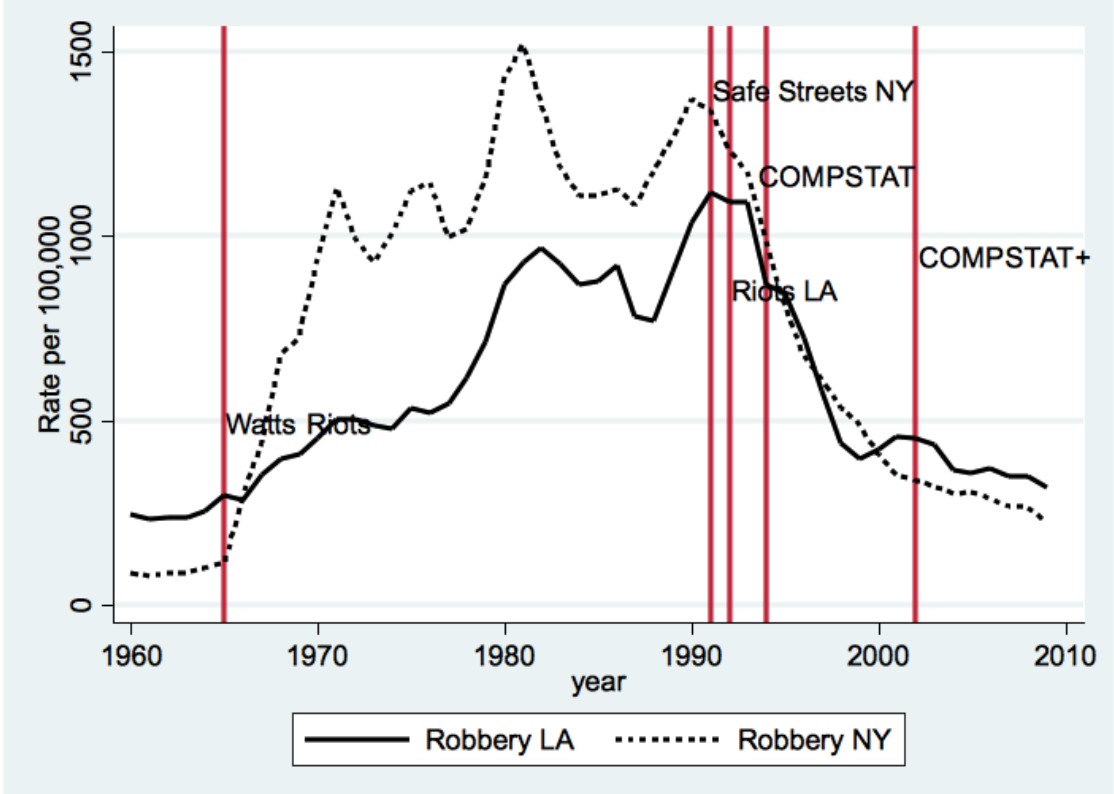


Perhaps the most remarkable trend within the larger arc is the sharp decline in each city between 1990 and 2000. Within this shorter period, almost any year that we estimate as a parameter in the decade of the 1990s after 1992 in either NYC or LA shows a significant downward trend that dominates any reform occurring in the following decade, including both the appointment of Chief Bratton in Los Angeles and the Consent Decree that went into effect in 2000. Even when we adjust for the full series of observations going back to 1960 for robbery and homicide, the decline in the near decade from 1992-2000 shows that declines in each city were steep and systematic, even under starkly different conditions. $^{25}$

So, while Bratton's reforms in NYC in the 1990s and in LA a decade later showed some promise in reducing crime, one should also point to Chief Willie Williams as the great crime drop leader in LA through his effort to institute community policing and transform the culture of the LAPD. The successes of Chief Williams were interrupted (and cost him his job) in the trend in LA in the years surrounding the Rampart Scandal. Between 1999 and 2001 both homicide and robbery rates in LA reversed course and increased for the first time since the early 1990s. After 2001, with the Rampart Scandal resolved and new management in place under Bratton, the decline in LA in robbery and homicide resumed. The salient point here is that in both LA and NYC, in very different policing regimes and political and social contexts, a crime decline began that has - with the interruption of the Rampart years - sustained for nearly two decades into 2010 .

\section{The COMPSTAT Effect}

The COMPSTAT innovation used spatial analysis of crime patterns with constant updating to drive the allocation of police resources to crime "hot spots". It is an innovation first developed by William Bratton in NYC when he headed the NYPD's Transit Bureau, and he brought it to departmental scale when he was appointed Police Commissioner in 1994 (Bratton and Knobler, 2008). Since then, it has been adopted by law enforcement agencies across the country and in several cities in Europe and Latin America (Weisburd et al., 2004). Arguably, its effects have most deeply felt in LA and NYC, where Bratton was the police executive during the implementation of the management design. ${ }^{26}$

If we were to focus on only examining the effect of the COMPSTAT program in NYC that started in 1994 we see a clear influence of this program in reducing robberies and homicides. Figure 5 shows the linear trends in homicide rates for NYC and LA in the years after each city adopted its version of COMPSTAT under chief Bratton. In NYC, the linear trend was 14.5 fewer homicides per 100,000 residents after 1994. In LA, the linear trend was 11.5 fewer homicides per 100,000 residents after 2002. These trends suggest that COMPSTAT efforts provided a meaningful contribution to the crime decline in 
each place But, if we look back to the date of the onset of the crime decline in LA in 1994, the linear trend would be similar to NYC's - including the three year spike in crime between 1999 and 2001 in LA.

Figure 5. Homicide Rates with Linear Trends in New York and Los Angeles following COMPSTAT, 1980-2010

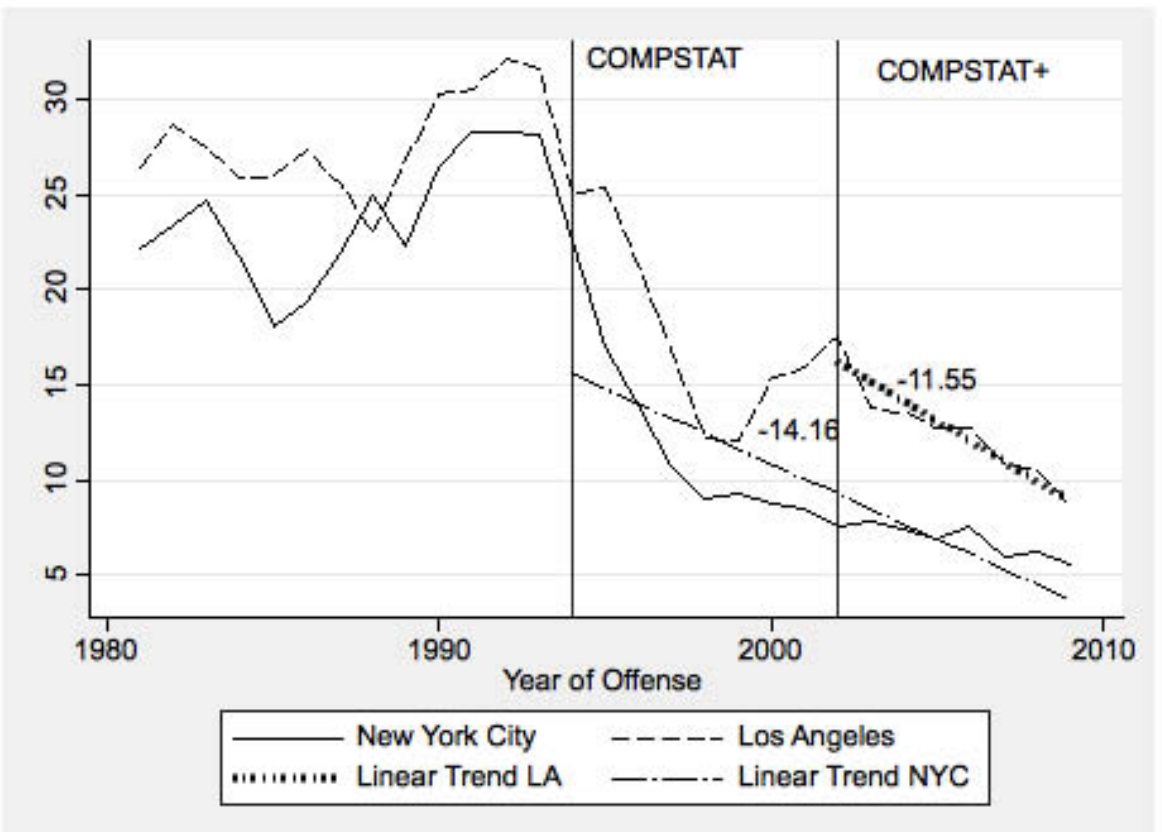

\section{Street Tactics}

In both LA and NYC, Terry stops were the hallmark of the policing regimes in the past decade. Street stops of pedestrians under Terry v Ohio (1968) permit officers to engage, question, then possibly frisk suspects for weapons based on reasonable suspicions that "crime is afoot." Officers can search a suspect based on probable cause that the suspect is either armed or has contraband in his possession or has committed a crime (Terry v Ohio, 1968). In NYC, with its high volume of pedestrian traffic, most stops have been street stops. In LA, with a lower population density and far greater use of automobiles, stops are a combination of street stops and motor vehicle stops. The stops, whether in a car or on the street, are invasive, often unpleasant, and usually did not result in an arrest. The racial disproportionality of street stops and car stops were, in each city, a driver of litigation.

Table 1 shows data on Terry stops in each city for two years in the past decade. At first glance, it seems that "street" policing in New York in the past decade not only has grown substantially, but the number of involuntary policecitizen contacts rose by nearly $500 \%$ within five years. The years in Table 1 were chosen for ease of comparison based on available data. In the four years from 
2008-2011, the rate of involuntary citizen stops in New York rose to 686,724, an increase of 45.5\% from 2007. The rate in Los Angeles rose by $100 \%$, a far lower increase. But the LAPD made a total of 875,204 stops including vehicle stops, so the focus on pedestrian stops vastly understates the extent of LAPD citizen interdictions. Traffic stops in New York are far less frequent. The percent Black or Hispanic in New York was $86.6 \%$ in 2011, a rate that has been rising slowly since the first analysis of these data in 1998 (New York State Attorney General, 1999).

Blacks and Hispanics in both cities remain the primary recipients of proactive police actions and attention. Data on pedestrian stops in both cities for years 2002 and 2007 presented in Table 1 show that the majority of stops in each place are of Hispanic and Black suspects. Although the LAPD has been subject to less scrutiny than NYPD on disparities in police stops, the stop proportions by race in both cities are quite similar. Ayres and Borowsky (2008) showed stark racial disparities in Los Angeles in 2004, after controlling for crime rates. Fagan et al. (2010) showed the same in New York for 2006.

Our data in Table 1 most likely understate race- or ethnic-specific disparities. We combine Black and Hispanics, but one should recognize this masks the stark disparity borne for Blacks in LA (Ayers and Borowsky, 2008). Over time, Blacks have been a far smaller percentage of the LA population (9.6\% in 2010) than are Blacks in New York (25.5\% in 2010). Conversely, the Latino population in LA is a far greater share of the City's population (48.5\% in 2010) compared to New York (28.6\% in 2010). A separate analysis of stops per capita by race would show a far higher rate of pedestrian stops for Blacks in LA, comparable to NYC's rate.

Table 1. Pedestrian Stops per 100,000 Persons, New York and Los Angeles, 2002 and 2007

\begin{tabular}{lrrrrr}
\hline & \multicolumn{2}{c}{ New York } & & \multicolumn{2}{c}{ Los Angeles } \\
\cline { 2 - 3 } \cline { 5 - 6 } \cline { 5 - 6 } \cline { 5 - 6 } Total & 2002 & 2007 & & 2002 & 2007 \\
\cline { 2 - 3 } Rate per 100,000 & 9,7830 & 472,096 & & 76,615 & 135,263 \\
\% Black or Hispanic & $1,210.1$ & $5,705.4$ & & $2,010.8$ & $3,384.9$ \\
\hline Source: & 73.4 & 81.7 & & 78.5 & 81.0 \\
\hline
\end{tabular}

The higher per capita stop rates in NYC may reflect more than simply tactics, but the size of human resources devoted to stopping citizens. The number of officers in uniform at the NYPD was 34,060 is June 2012, the lowest total since the 34,825 officers on the force in 1992, when crime rates began their decline. The LAPD has 9,927 officers from 2009- 2012, (LAPD SRGE Report, 2012). So, the disparity in personnel - a ratio of 3.5|1 - between the two cities 
doesn't explain the 1.7|1 disparity in per capita stop rates. Just considering the rate of pedestrian stops, LAPD officers appear to be very active, relative to the size of the force. When we include motor vehicle stops, the LAPD appears to be stopping a lot of citizens relative to the size of its police force.

Pedestrian or "street" stops are hardly the only policing story in each city. The totality of policing over the past decade in each place has been substantial. Several specific enforcement priorities, consistent with its Order Maintenance Policing strategy, have produced significant numbers of arrests for several types of low-level misdemeanors and violations. The NYPD have averaged over 45,000 marijuana possession arrests since 2000 (Geller and Fagan, 2010) and an additional 16,000 criminal trespass arrests each year since 2007. More than one in three of those arrests were resolved in favor of the defendant (NYCLU, 2012). In 2011, prosecutors declined to charge more than 13 percent of people arrested for trespassing in the city. NYPD officers also issue numerous citations for a variety of "quality of life" violations that are not criminal offenses, but that carry criminal liability if the citation is not answered. Comparable data in LA are difficult to obtain, though the combination of pedestrian and motor vehicle stops suggests a rate of involuntary contact with police - whether through stops or citation of other enforcement initiatives - that is comparable to that in New York.

The move over the past decade to a policing regime in each city that emphasizes proactive contacts with citizens whether at the moment of an offense or before it occurs has produced a thick net of social control that envelopes each city's minority neighborhoods. For adolescents and young adults, the frequent police contacts have become a part of the normal process of adolescent development, a form of anticipatory socialization that internalizes the stigma of police contact, whether founded or not by the detection of crime. If the contacts themselves are harsh and unpleasant, the negative aftermath generates not just ill will, but a withdrawal of citizens from cooperation with the police (Tyler, 1990). In an era of steeply declining crime rates in each city, the theoretical and empirical basis for the escalation of police contact may be questionable and strain public confidence in the police, especially among minorities most likely to experience police contact.

\section{The Political Economy of Policing and Crime}

The shared temporal shifts in patterns of bellwether crimes in Los Angeles and New York over 50 years are remarkable given the distinct political trajectories and institutional structures of policing in each city over this time. One might assume that, given the influence of William Bratton as the commissioner of the NYPD and later chief of the LAPD, a remarkable figure in policing in each city and within the profession, the developmental teleology of policing would be similar. But it isn't. The forces that shape policing are a combination of both the unique social and demographic circumstances of the two cities, but also their 
responses institutionally and politically to parallel pressures of crime, scandal, and reform. And here, the two cities had - as with policing - both shared and distinct changes over time in their social structure. The two cities were each undergoing rapid and profound transformations, not just since the peak of the crime decline, but for many years before. The twin patterns of ecological change and the teleology of policing and crime raise important questions about the ordering of these influences in the broader transformation of the city.

\section{Housing and Gentrification}

The physical space of each city has transformed dramatically in the past two decades. Gentrification in the central core of each city, as well as in selected neighborhoods, has both displaced populations from poor, high crime areas and reconfigured the built environment in in those places in dramatic ways. In each city, the process of transforming both the residential and commercial built environments has required that the police to engage in more "order maintenance" styles of policing in the central business districts.

\section{New York}

In the midtown business core of New York, between the Theater District and office towers to the east, the gentrification of the Times Square area of New York was a process designed and implemented in the 1990s. Together with zoning changes, tax incentives to spur development helped replace the carnival atmosphere of Times Square with retail stores, hotels and restaurants that draw from mainstream American culture. ${ }^{27}$ Physical disorder also was replaced by the construction of several office towers housing professional workers.

As part of the development effort, the shift in policing strategy beginning in 1994 to order maintenance facilitated the removal of the signs of social disorder. This meant using zoning laws to force the closing of destinations for "undesirables" including pornography shops and cheap eateries. The aggressive policing strategy focused on prostitution, vagrancy and loitering, and other petty misdemeanors to remove prostitutes, homeless persons, street card games, and groups of persons loitering around X-rated movie houses. The result was the replacement of old visible signs of disorder with businesses and buildings that reassured tourists, merchants, and consumers of cultural activities that the area was safe. The local business community encouraged the creation of new forms of court services to reduce the recurring nature of much of this crime by providing remedial services to those who formerly occupied the streets (Briffault, 1999).

Although this is an appealing story consistent with "broken windows" theories of policing (Kelling and Cole, 1996) and its impact on disorder (Skogan, 1990), the simultaneous and reciprocal interventions of policing and development

in the Times Square area makes it difficult to disentangle the causal the effects of 
policing on crime in a context of radical shifts in the built environment. In other words, the two faces of "broken windows" were remediated simultaneously, with perhaps unique, additive or even multiplicative effects.

Development in the neighborhoods outside the NYC's business districts was based less on commercial development than on the transformation of housing and other faces of the built environment. Much of the development was driven by gentrification, but its forms varied by neighborhood. Gentrification in Harlem, Red Hook, Washington Heights, and the South Bronx brought about radical transformations in housing and population composition, as well as reductions in crime. Gentrification in Chelsea, largely by gay populations, converted a working class residential and rough area into a wealthy enclave. But the economic and cultural dislocations caused by this displacement were dramatic. New businesses in those areas were created to serve the new residents, but the jobs they brought demanded skills that the remaining local residents did not have, increasing economic tensions and intensifying relative deprivation between adjacent areas.

Police responses in these places, where the crime rate is now low, are no different now than they were during the era of dramatic crime reduction in the 1990s. Aggressive enforcement of low-level crimes, and aggressive interdiction of those who are "out of place," helped drive more than 500,000 citizen stops every year since 2003 . Harlem, a relatively safe neighborhood today, still has a very high concentration of police activity, including Terry stops, marijuana enforcement, trespass enforcement (Operation Clean Halls), and bans on public drinking. Gentrification inevitably led to the displacement of older residents by wealthier (and whiter) newcomers. There is some evidence that those who left took crime with them, and have adversely affected the areas to which they have dispersed. $^{28}$

The relationship between housing and crime in New York is complicated not only by real estate booms over the period since the mid-1980s, but by strategic investments in housing for poor people. Since crime in New York, as elsewhere, was concentrated in the poorest neighborhoods, we might expect those neighborhoods to be the most crime-sensitive to both housing development and crime. Figure 6 shows the distribution of $\$ 5.8$ billion in housing construction and rehabilitation programs for the poor across three mayoralties, starting in 1987, under a program known as the "10-Year Plan" (Van Ryzin and Genn, 1999). Fig 5 shows that these investments were made in the NYC's poorest neighborhoods, which were those with the highest homicide and other violence rates during the peak violence years in the late 1980s and early 1990s. 
Figure 6: Concentration of Ten-Year Plan Units in New York City, 1985-1995

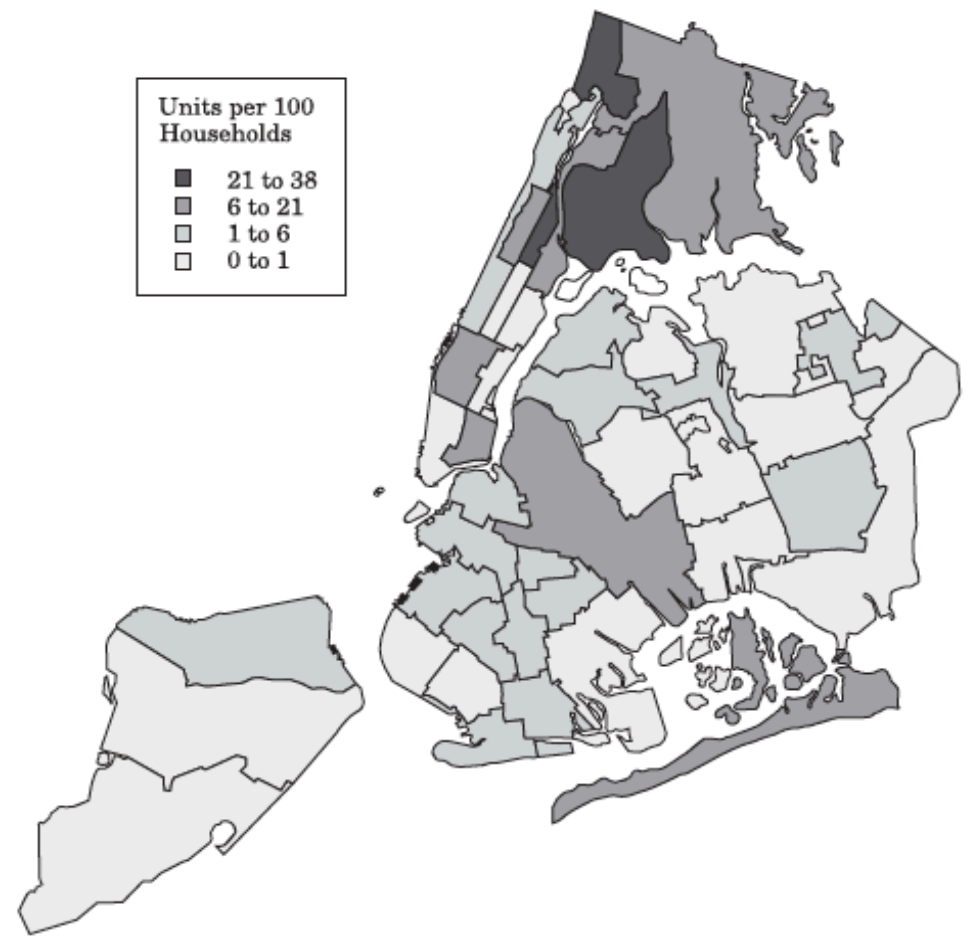

Source: Greg Van Ryzin and Andrew Genn (1999).

The decline in crime mirrors these investments. Figure 7 shows homicide "trajectories" for the City's 275 neighborhoods from 1985-2000 using boundary definitions of neighborhoods generated by the Department of City Planning. ${ }^{29}$ The trajectories were identified using trajectory modeling methods based on Poisson mixture models (Nagin, 2005). Fagan and Davies (2007) identified four crime trajectories that grossly describe crime trends across NYC neighborhoods, with $13 \%$ comprising the most dangerous and the others showing a more gradual decline that began in 1991. These were not only the most heavily policed places in the NYC (Fagan et al., 2010), but they also were the beneficiaries of the TenYear Plan investments. To illustrate this, Figure 8 shows that homicide declines were greatest in the same neighborhoods where housing investments for the poor were the highest. 
Figure 7. Homicide Trajectories, New York City Neighborhoods, 1985-2000

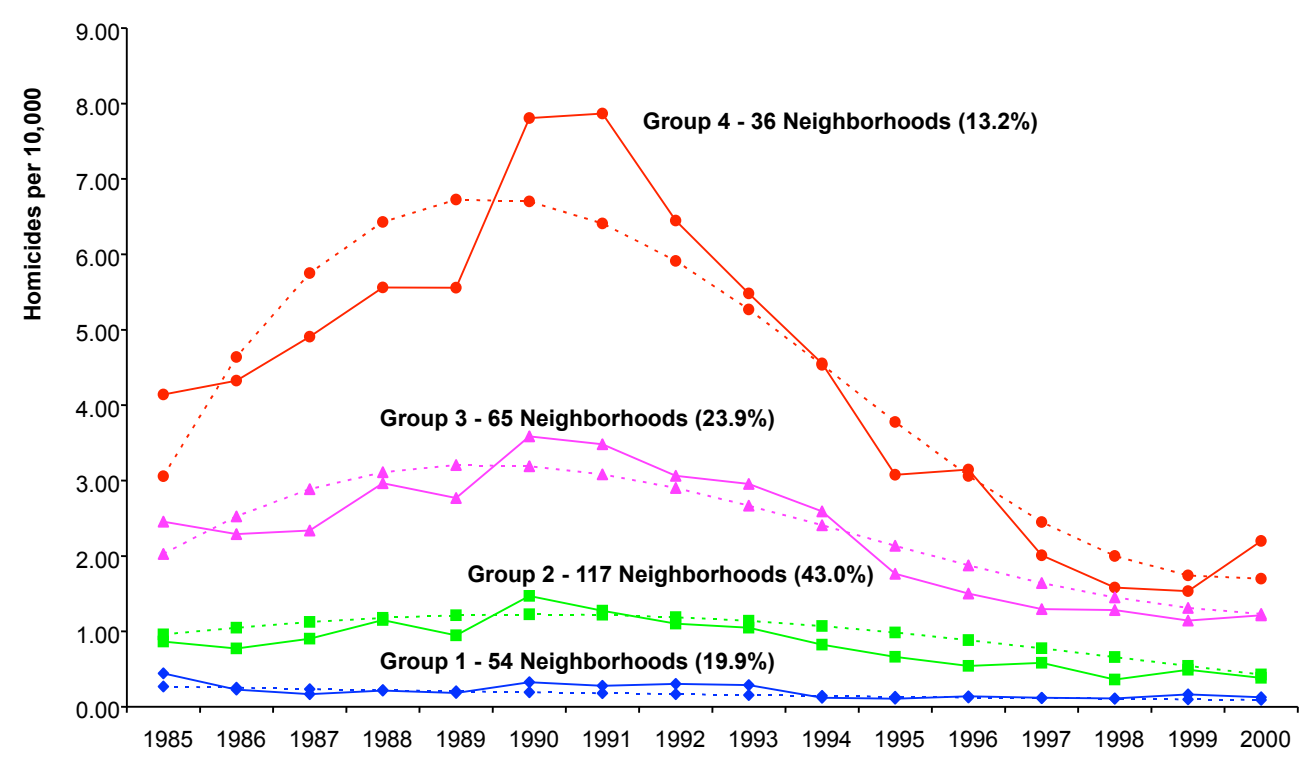

Source: Fagan and Davies, 2007

There are good reasons why people in poor neighborhoods may be more responsive to housing investments. First, housing imparts stakes in one's community (Toby, 1954). Homeowners are more likely to exercise guardianship over their homes and neighborhoods when they have such stakes. Second, housing is a critical pathway to wealth, and an escape route from the poverty traps that characterize many poor and high crime neighborhoods (Massey and Denton, 1993; Sampson and Morenoff, 2006). Housing ownership reduces transience and mobility, in turn promoting the kinds of strong social ties that can inoculate neighborhoods against crime through collective social actions (Sampson et al., 1997).

Of course, policing throughout this period was concentrated in the areas with the highest homicide rates (Letwin, 1990; Karmen, 2000; Fagan et al., 2010). Accordingly, the simultaneity of policing and the economic transformation of housing complicate efforts to sort out the temporal sequence of changes between crime rates shaped directly by the police from those influenced by changes in the built environment. Empirical arguments depend in part on the starting point for measuring change, on the lens - whether borough, neighborhood, census tract, or police precinct - and how one conceptualizes housing and physical disorder (Schwartz et al., 2003; Fagan and Davies, 2007). 
Figure 8. Map of Homicide Trajectories by Neighborhood, New York City, 1985-2000

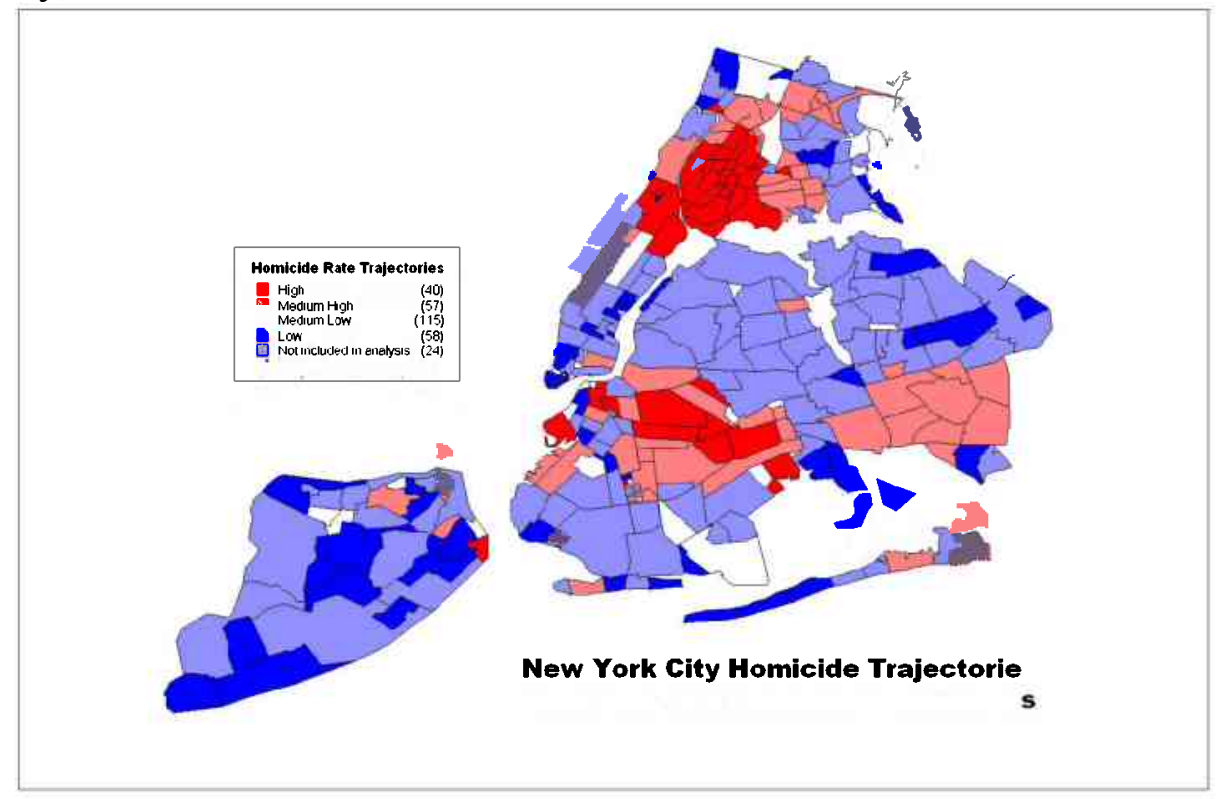

Source: Fagan and Davies, 2007

\section{Los Angeles}

The same tension in causal mechanisms is evident in the story of housing and crime in Los Angeles during the same era. Was the drop in central LA caused by gentrification to downtown neighborhoods and areas new University of Southern California? This is a complex picture because crime rates do not easily reconstitute themselves in areas settled by displaced residents. In fact, when we examine the data on Los Angeles it is clear that across all police divisions crime rates dropped significantly after 2002 - the period in which Bratton instituted COMPSTAT Plus (Gascon, 2005). Yet, the crime drop in the central business district area (Central Police Division) of LA occurred during this period of police reform, while crime rates in South LA did not enjoy a similar decline.

In Los Angeles, the redevelopment of neighborhoods like Skid Row in the downtown area, and West Hollywood in the outer residential areas, as well as recent development of places such as Bunker Hill adjacent to downtown, have fueled similar conflicts and tensions over how to appropriately police homeless populations when areas become prime targets for real estate investment and urban renewal (Blasi, 2007; Harcourt, 2005). Figure 8 shows the decline in total reported violent, property, and nuisance crimes in the Central Police Division of LA (where Skid Row is located) between January 1, 2000 and December 31, 2007 (Berk and MacDonald, 2010). Like New York, there is empirical evidence that the LAPD's efforts through its Safer Cities Initiative to crackdown on 
misdemeanor crimes and enforce vagrancy laws that ban the formation of large homeless encampments led to meaningful reductions in crime (Berk and MacDonald, 2010).

Figure 9: Crime Trends in Los Angeles Central Police Division, January 1, 2000 to December 31, 2007

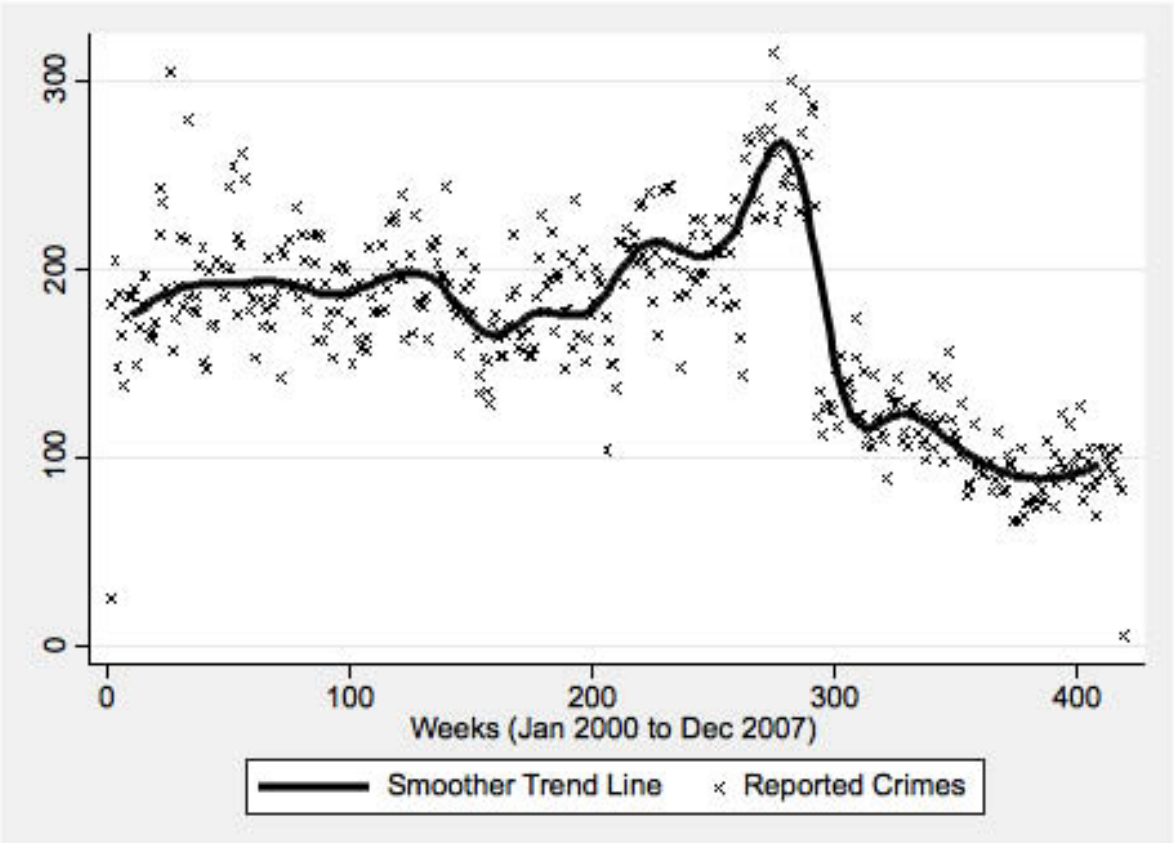

Whether a greater investment in LA county mental health and health and human services agencies could have been equally effective as the LAPD's approach to reducing crime and disorder in Skid Row is an open question. But in both cities a focus on crime reduction through getting tough on vagrancy always brings out tensions between those concerned with crime control and those concerned with the plight of homeless.

We can expect this to continue through the coming decade as neighborhoods develop and populations both change and older residents are dislocated. Gentrification will always bring about tensions for police as community expectations about the police response change in response to changing dynamics of neighborhood property owners and residents.

\section{Immigration}

The second major transformation of the city during the second half of the $20^{\text {th }}$ century - and into the first decade of this century - has been the increase in both size and neighborhood concentration of immigrants. The relationship between immigration and crime has been a topic of policy interest at different times in $20^{\text {th }}$ century, and the current era is no different. The 1931 report by the National Committee on Law Observation and Enforcement, popularly called the 
Wickersham Commission, observed no evidence linking immigration to increased crime patterns (Tonry, 1997).

Despite the Wickersham Commission's observations, sociology was dominated by the thinking that immigration was linked to crime through neighborhood social disadvantage. Sociologists studied immigration as a central feature of the social structure of neighborhoods in the first half of the $20^{\text {th }}$ century. Most concluded that immigrants themselves had relatively low rates of criminal offending, but that immigrants settled into disadvantaged areas that exposed their children to higher rates of offending. Several notable sociologists theorized that any evidence of higher crime rates in immigrant neighborhoods was a result of the exposure of second generation immigrants to economic disadvantage, a culture of conflict, and underclass norms that were more favorable to violations of the law in the presence of relative economic disadvantage (see Reckless and Smith 1932; Sutherland 1934; Sellin 1938; Shaw and McKay 1942).

But recent empirical research on the immigration-crime nexus suggests that the earlier links between immigrant settlements and neighborhood crime rates have changed, suggesting a new and different interpretation of the social disorganization theories of the first generation of immigration-crime studies (cf. Morenoff and Astor 2006; Martinez, Stowell, and Lee 2010). During the 1990s, a number of U.S. cities, including both New York and Los Angeles, experienced substantial growth of immigrant settlement into inner-city poverty-stricken neighborhoods (Malone et al. 2003; Passel and Suro 2005; Davies and Fagan, 2012). Neighborhood patterns of poverty and residential segregation in New York and Los Angeles, like many other large cities, shifted the demographic makeup of high poverty neighborhoods that had since the 1960s been the areas of standing racial or ethnic disparities in income and housing segregation (Cutler, Glaeser, and Vigdor 2008; Glaeser, 2011). The New York neighborhoods of Harlem and the South Bronx that had been settled by African Americans and Puerto Ricans for decades became areas of concentrated poverty that were emblematic with crime in the city (Davies and Fagan, 2012). In the Los Angeles neighborhoods of East Los Angeles, South Central, and Watts, African Americans and Mexican Americans had been living in entrenched poverty since the 1960s. These neighborhoods were considered hot beds of crime and violence; Watts, as we mentioned earlier, was the center of an apocryphal riot in 1965.

For reasons owing perhaps to both economics and race or ethnicity, these areas of entrenched poverty became destinations for new immigrants. Immigrants tended to settle in places they could afford and places where people looked like them (Davies and Fagan, 2012). In Los Angeles, this meant that areas of both Mexican American and African American poverty became increasingly concentrated with foreign born residents. In New York, the neighborhood of Washington Heights became a reception zone for immigrants from the Dominican Republic in the 1970s, while American residents of Puerto Rico in-migrated to the neighborhoods of the South Bronx and East Harlem in the 1960s. Haitian and 
other Caribbean immigrants settled in the East Flatbush area of Brooklyn in the 1970 s, accelerating an outmigration of whites to the suburbs that began two decades earlier.

These were neighborhoods with high crime and violence for decades, but as we show for each city, that is no longer the case. As crime rates declined in each city, we show that the decline in crime in the new immigrant neighborhoods was greater than in other parts of the respective cities. There is evidence both in New York and Los Angeles that neighborhoods with high concentrations of immigrants have experienced larger crime declines than similarly situated neighborhoods without heavy influxes of immigrants. As with housing, the worst places in each city became safer, and the evidence suggests that this marginal gain in public safety was attributable to immigrants.

\section{Los Angeles}

Figure 10 shows the distribution of foreign born residents and Latinos (predominately Mexican American) in LA census tracts in 1990 and 2000. What is striking from this figure is how more concentrated immigrant enclaves became in LA, even in areas previously not considered immigrant enclaves.

Figure 10: Distribution of Foreign Born and Latinos In Los Angeles

Neighborhoods (1990-2000)
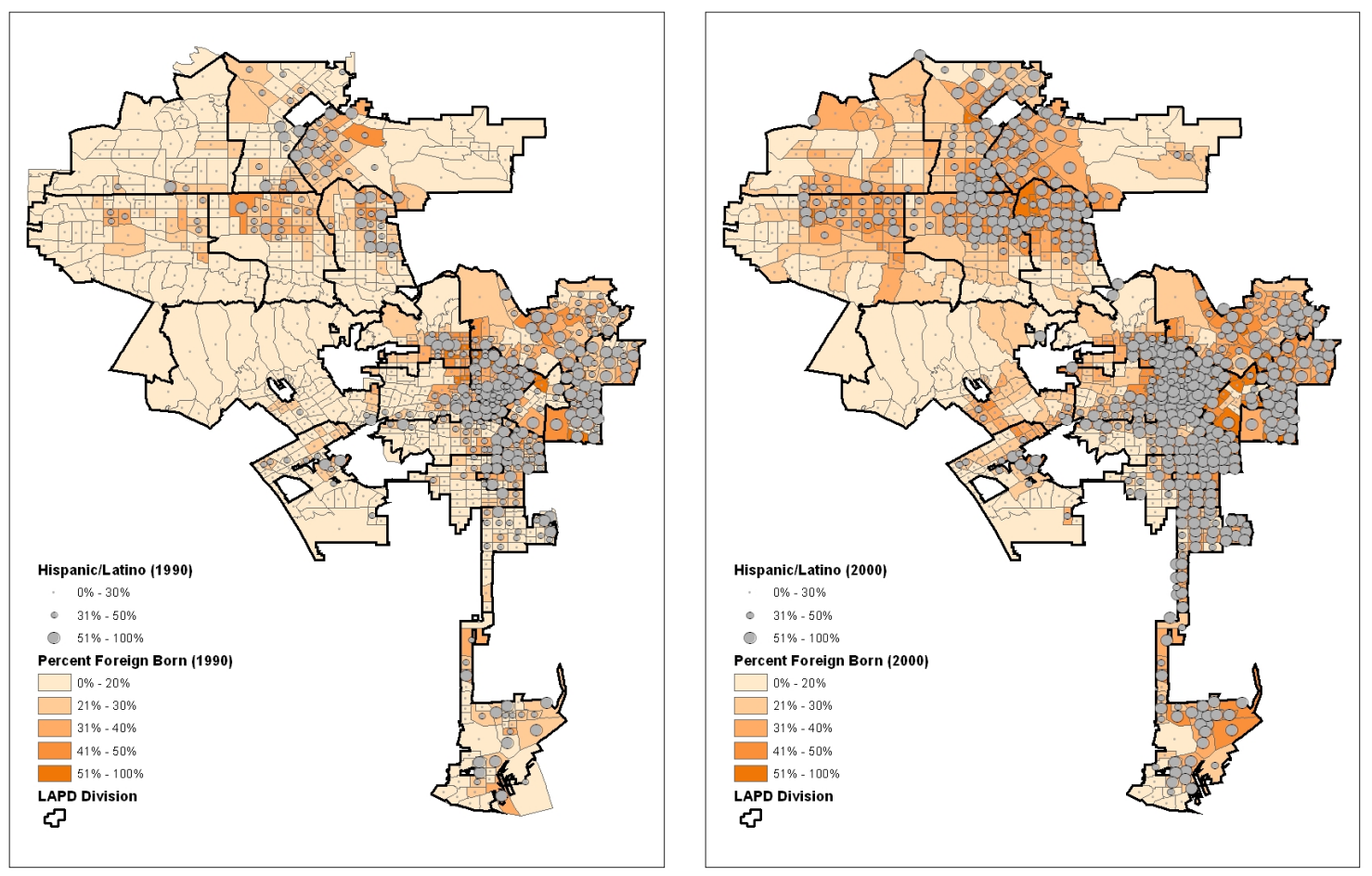

I

Source: MacDonald, Hipp, and Gill 2012 
MacDonald and colleagues (MacDonald, Hipp, and Gill, 2012) showed that these areas with high expected probabilities of immigrant settlement ${ }^{30}$ had greater reductions in crime between 2000 and 2005 than other similarly situated areas. ${ }^{31}$ Figure 11 shows the average change in neighborhood crime rates as measured by the total number of serious crimes ${ }^{32}$ declined substantially more in neighborhoods with higher expected immigrant settlement patterns. What these findings suggest is that part of the crime decline in LA is a story of immigrant concentration. But there are several immigration stories in Los Angeles, owing to the multiple countries of origins of various immigrant groups, especially from Central and South America. Identifying unique sending-country effects is complicated by the absence of country of origin measures prior to the 2000 census. Even with those data, parsing the unique country-of-origin effects would be complicated by the high percentage of Mexican immigration and the residential integration of all immigrant groups in neighborhoods where Spanish is the first language.

Figure 11: Average Change in Crime by Quartiles of Predicted Immigrant Concentration, Los Angeles Census Tracts, $2000-2005$

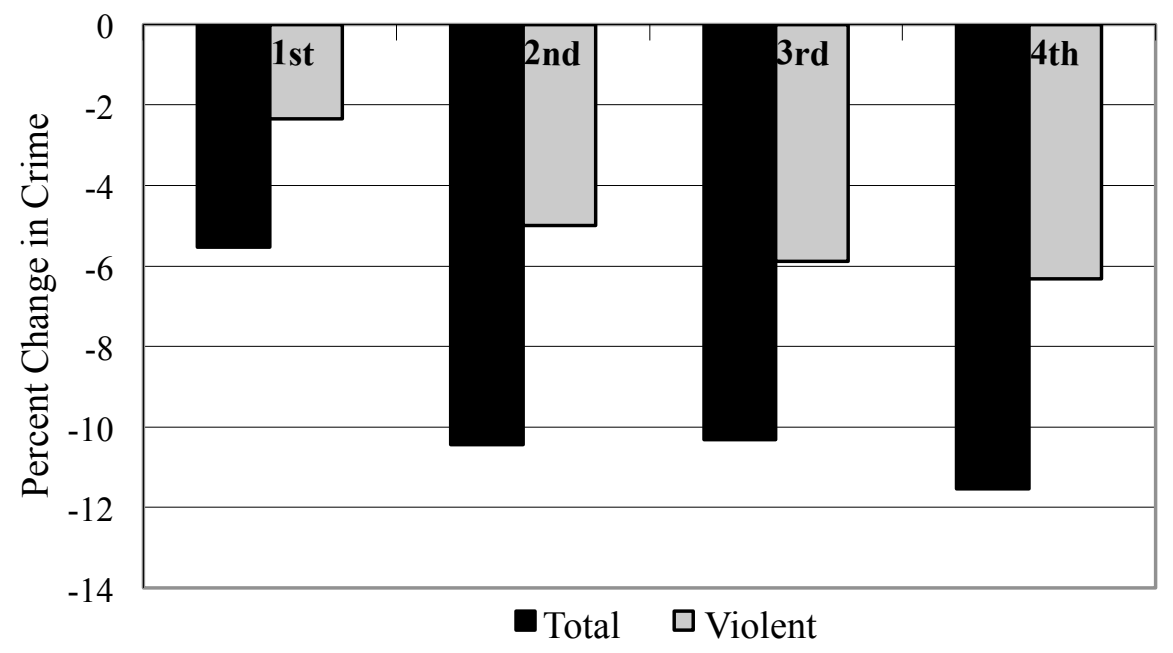

Source: MacDonald, Hipp, and Gill 2012

\section{New York}

In New York, immigration rose steadily beginning in the 1970s, with settlements of Caribbeans in East Flatbush and Dominicans in Washington Heights. Two decades before, Puerto Ricans in-migrated to NYC and settled primarily in East Harlem and the South Bronx, spreading out from there to other neighborhood across the City. Figure 12 show maps of immigrant concentration in 1990 and again in 2000. Immigration since 1990, primarily South Asians, 
Mexicans and other Central Americans, and several East Asian groups, has been concentrated in several neighborhoods in Queens and Brooklyn, with smaller concentrations in Manhattan and the Bronx.

Figure 12: Distribution of Foreign Born Population in New York Neighborhoods $(1990-2000)$
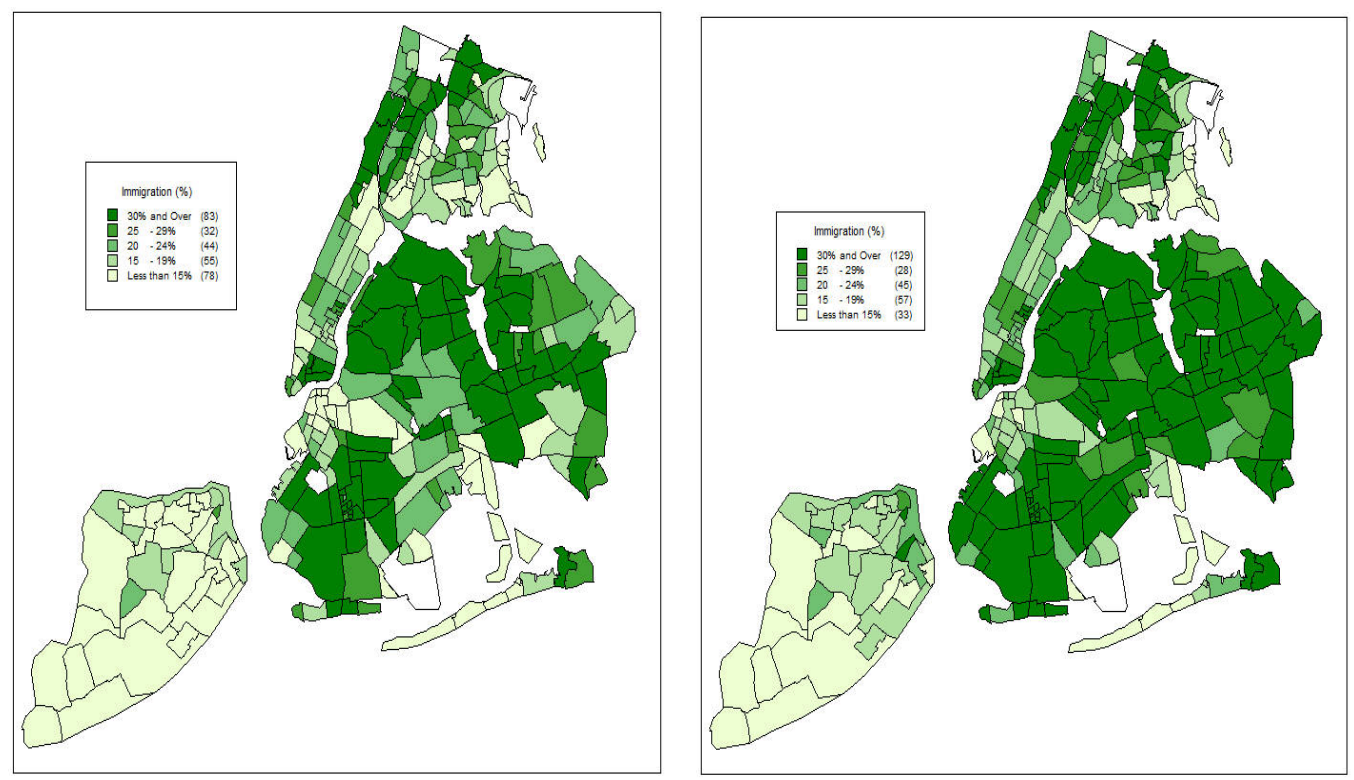

As in Los Angeles, immigration has been a protective factor in the natural history of crime in the city's neighborhoods. Figure 13 shows the effects of immigrant concentration on specific types of crime in New York during the same period as reported by Davies and Fagan (2012). To assess potential cohort effects, immigrant neighborhoods were measured both as the percentage of all foreign born residents and then as the percentage of foreign born residents who had lived there for less than five years. In each case, there were strong significant effects for the total immigrant population on all crimes, plus three specific crime types. But the effects were less muted for recent immigrants, owing perhaps to the fact that by 1997, they had arrived in neighborhoods that already had experienced strong crime declines, and that realized significant improvements in housing (Fagan and Davies, 2007). 


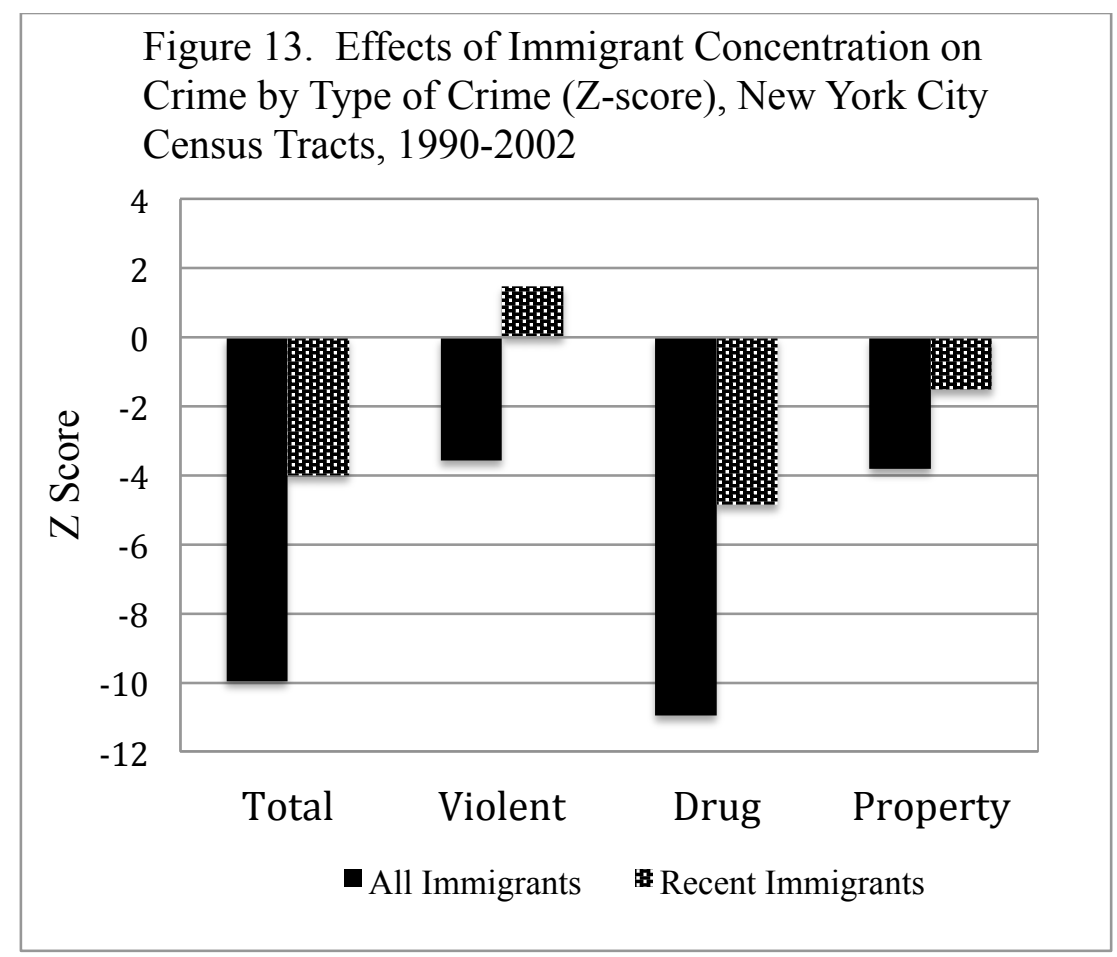

Source: Davies and Fagan, 2012

Davies and Fagan (2012) also showed differences by ethnicity and race in the effects of immigrant concentration on neighborhood crime. Figure 14 shows the effects of immigrant concentration on both total and violent crime were greatest in neighborhoods where White (mainly Russian and other Eastern Europeans) and Black (mainly Caribbean) immigrants settled. Concentrations of Latino immigrants showed little effect on crime rates, perhaps for different reasons. One was the generally lower concentration of Latino immigrants and their entry into a heterogeneous set of neighborhoods, with both low and high crime rates. Asian immigrants tended to settle in stable low crime areas, muting any effects of either longstanding or more recent immigrants. 


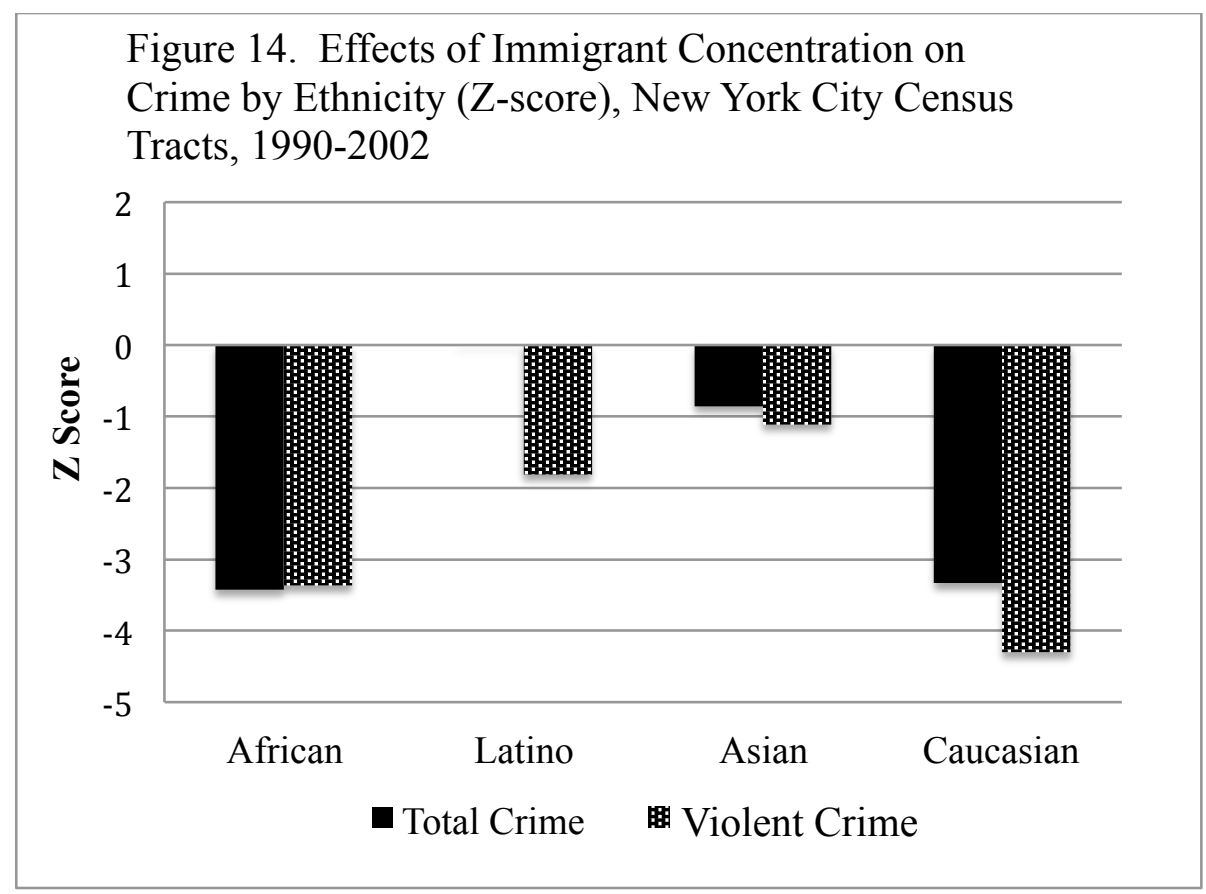

Source: Davies and Fagan, 2012

In both cities, generational effects are evident, though they seem to work on opposing directions. In New York, neighborhoods with newer immigrants had smaller crime declines than the more settled immigrant areas. While this may be an effect specific to the ethnic group, it may also suggest that the effects of immigrant generation covary with pre-existing crime and other social conditions in the neighborhoods.

But the story is somewhat different in Los Angeles. In areas settled by more recent Central American immigrants have had lower crime rates through the late 1990s than areas settled several generations ago by Mexican immigrants (MacDonald et al., 2012). Boyle Heights, for example, had a lower rate of crime drop than Southeast Los Angeles, where newer generations of immigrants had arrived since 1990. Though both areas had similar percentages of Hispanic residents, Southeast Los Angeles became an area of greater immigrant concentration over the decade of the 1990s. These trends suggest that acculturation by the second generation accompanied by poverty trapped neighborhoods reduces any generational effect of immigration on reducing crime (MacDonald et al., 2012). In short, by the third generation the rates of crime climb back to what would be expected if a neighborhood had concentrated poverty and few immigrants.

This suggests that the benefits of immigrant concentration on reducing crime may be transitory, and if not accompanied by social mobility to diffuse and assimilate into the city (and regional) social structure and economy. In other words, racial and ethnic segregation might erode the gains in crime reduction and 
social control that are produced by new immigrants. In the first generation, segmented assimilation of self-selected immigrants into new ethnic enclaves may produce social capital benefits that help control crime and even provide some protection for second generation residents during adolescence (MacDonald et al., 2012). But, as time goes by, neighborhoods entrenched in poverty regardless of the historical ethnic heritage will have crime rates that return to normal states. The South Central and Southeast neighborhoods of LA are central to this story of crime decline in the LA but also the immigration story. The crime declines in these places were strongly correlated with the arrival of new immigrant residents. So, while Los Angeles as a whole was growing safer between 1994 and 2005, the dominant trend was in the areas that were undergoing significant immigrant arrival and gentrification.

\section{Policing Immigration and Crime}

One might expect that the potential benefit of immigration for reducing crime rates in neighborhoods has not been lost on the police and public officials in either city. But on this question, the two cities differ. In Los Angeles, for example, former police chief Daryl Gates help establish an LAPD departmental policy in 1979 to not initiate "police action with the objective of discovering the alien status of a person," and to not arrest or book a person for "illegal entry" into the United States (Rampart Independent Review Panel 2001). The LAPD have been vigilant about not enforcing federal immigration laws so that they can encourage immigrants to actively report crimes.

How do police patrol these neighborhoods, and what is the nature of police-citizen interactions? Crime and arrests are endogenous, so it is difficult to sort out whether the lower crime rates in immigrant neighborhoods are an externality of immigration, or whether the police alter their strategies in areas that they may believe to be different and (more important) less problematic. While there is no direct data on police patrol strength in LA and immigrant enclaves, it is noteworthy that the LAPD has had a friendly immigrant policy on the books since 1979.

In NYC, there is no specific policy on policing immigrant neighborhoods. But there is evidence that police in NYC more aggressively patrol neighborhoods with poor and African American populations, after controlling for crime, but they are less aggressive in areas settled by immigrants from Latin America generally. Figure 15 shows that enforcement for total, violent, and property crimes is significantly higher in places with greater proportions of immigrants, after controlling for any differences in crime. Only for drug crimes does there appear to be less enforcement in immigrant neighborhoods. And enforcement here, defined as the sum of Terry stops (stops and frisks) plus misdemeanor arrests, is greater in neighborhoods with higher concentrations of recent immigrants. This effect is especially strong for newer immigrants who have been in country for less than 
five years. Although crime is on balance lower in neighborhoods with higher immigrant concentrations, the ratio of stops and arrests to crime is higher in these same places.

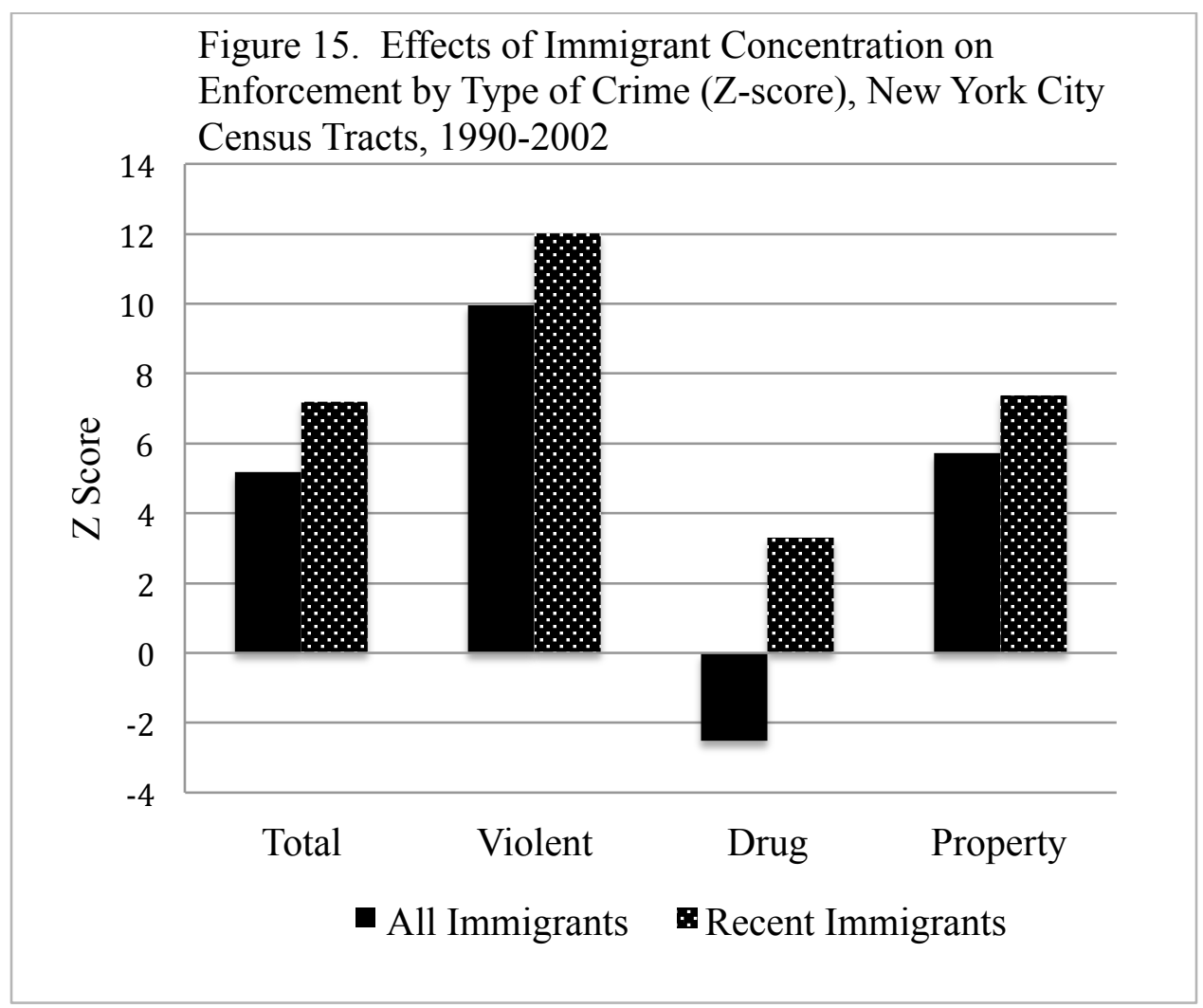

Source: Davies and Fagan, 2012

These enforcement patterns vary by the race and ethnicity of the immigrant group, especially for immigrants of African descent. Figure 16 shows that enforcement, controlling for crime, is slightly higher for recent immigrants of Latino origin, but lower for both Whites (again, primarily Eastern Europeans) and significantly lower for immigrants of African descent. Evidently, while African immigration protects neighborhoods from crime, it also protects them from the excesses of racially-tinged enforcement that characterizes the NYC neighborhoods where native born African Americans reside (Fagan and Davies, 2000; Fagan et al., 2010). 


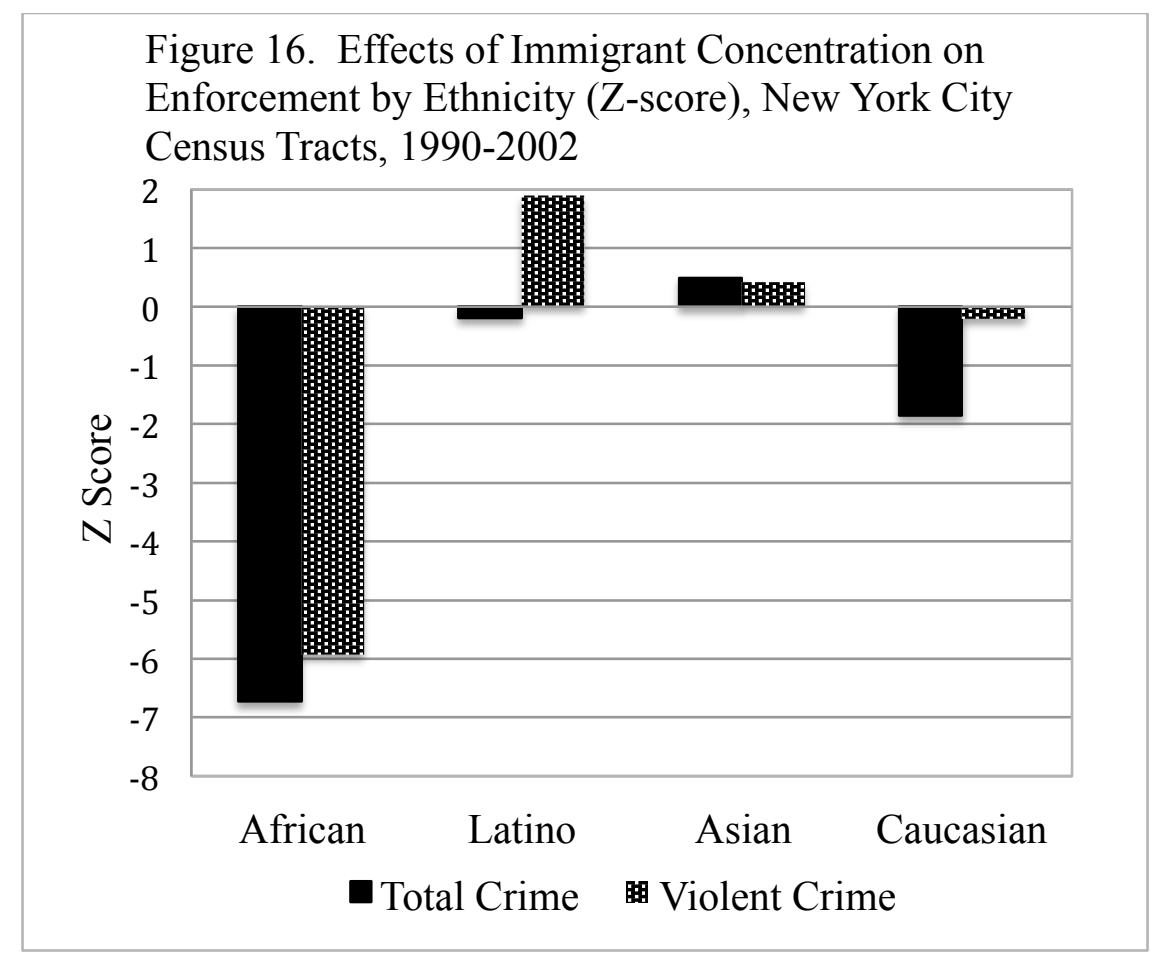

Source: Davies and Fagan, 2012

Immigration in LA and NYC will continue, contingent on national political considerations, throughout the coming decade but at a pace that may not equal what we saw in the past decade. And as second and third generation immigrants occupy the neighborhoods where their parents landed, their immersion into the (nonwhite) American culture suggests the possibility that crime problems will emerge. How the intergenerational path from immigration to crime patterns emerges in each city is difficult to predict.

The interaction of immigration and gentrification also is a cautionary story. Tensions and conflicts between African American and Latino groups in LA, and also in Northern Manhattan, suggest the possibility of a return to the social dynamics of a century ago in Chicago, where immigrant groups clashed, organized into gangs, and crime and conflict were prevalent. Finally, the role of police in enforcing immigration laws is complex and changing. Most police agencies see this as outside of their mission and jurisdiction, and they also see it as dissuading citizens from voluntary cooperation with police in investigating everyday crimes.

Sampson (2008) suggests that there is a link between rising immigration patterns in cities and the declines in crime rates that occurred during the 1990s. More recent work by Stowell et al. (2009) and Martinez et al. (2010) suggests these trends are true across cities and within San Diego. Our review of the data suggests a similar pattern in LA and NYC. While immigrant settlement has not 
played a central role in explanations of neighborhood patterns of crime or, more generally, our research in both cities suggests a link between within-neighborhood changes in crime and predicted immigrant settlement patterns, net the effects of population and housing characteristics traditionally correlated with crime. Immigrant settlement patterns are associated with appreciable reductions in the crime in neighborhoods in both cities.

\section{The Future}

For a half century, policing in the two cities has gone through a cycle of crime booms and more recent busts that have oscillated around periods of scandal and reform. Crime has declined for nine consecutive years in Los Angeles, including a $9.6 \%$ decline in 2010 . While crime has also declined throughout the past decade in New York, the pace of change has been slower in the than during the first decade of the unprecedented decline that started around 1992. Los Angeles is slowly catching up to the low crime rates that now characterize New York. The connection between the two phenomena is part of a larger and more complex evolution in each city: the trends in crime and the episodes of policing scandal and reform have also coincided with changes in the social fabric of New York and Los Angeles.

The past decade has been a time of battles with civil litigation in Los Angeles and New York over accusations of unconstitutional police practices. In 2009, Los Angeles emerged from nine years under a consent decree - just one year short of the expiration of the second five-year term. In lifting the consent decree the U.S. District Court Judge Gary A. Fees overseeing the decree noted "LAPD has become the national and international policing standard for activities that range from audits to handling of the mentally ill to many aspects of training to risk assessment of police officers and more."33 The LAPD has entered into new partnerships with various community organizations (Nagourney, 2011), and nearly $80 \%$ of LA residents expressed strong approval for the performance of the department. This approval included $76 \%$ and $68 \%$ of the Black and Latino respondents to the poll. These signs show that the LAPD has recovered, both in reputation and in performance, following what was perhaps the biggest police corruption scandal in the U.S.

While Los Angeles has emerged from civil rights litigation in 2009 following a lengthy period of intensive federal court monitoring, New York City emerged from the Daniels litigation in 2007 only to become immediately mired in three new separate lawsuits alleging both racial discrimination and a pattern of unconstitutional street stops. The NYPD has intensified its spectrum of Order Maintenance Policing tactics, including trespass enforcement in public housing, street stops, and misdemeanor marijuana enforcement. All three prongs of this strategy have led to litigation and their wisdom and benefits continue to be hotly contested. The divided response of the NYC's diverse communities to the Stop 
and Frisk program, the centerpiece of the NYPD strategy, shows the depth of the racial breach between citizens and police: White voters approve $59-36$ percent, while disapproval is $68-27$ percent among Black voters and $52-43$ percent among Hispanic voters.

In LA, the future of the LAPD and its ties to the diverse communities of the city was set in motion by the changes brought about through both the external pressures of the litigation and the internal push for reform and responsiveness by Chief Bratton. The LAPD has become more diverse in the past decade, including a plurality of minority officers, a compositional change that has been linked to the positive response by the diverse communities of Los Angeles. There has been an active effort in the LAPD to diversify its department and finds was to enhance its recruiting effort, including using a new recruiting system developed by researchers at the RAND Corporation (Lim et al., 2009).

Like New York, racial disparities in police contacts remained through 2004, even after controlling for differences in crime rates between locations (Ayres and Borowsky, 2008; Fagan et al., 2010). Still, the structural and cultural reforms in the LAPD suggest that LA has entered a new era marked by collaboration between the LAPD and the community, built on a platform of accountability, transparency, and positive performance in maintaining safety and order. What is perhaps most important for the future are the signs of the community investment in this collaboration (Nagourney, 2011). Whether this future will hold, and for how long, is uncertain. But it is notable that there has not been a similar period on the past 50 years where the LAPD was viewed in such a favorable light by a wide cross section of racial and ethnic minorities in the city.

The future in New York is not quite as bright. High profile scandals continue surrounding the policing of racial and ethnic minorities, including the surveillance of Muslim communities both within the City and the surrounding region (Associated Press, 2011), allegations of falsification of victim reports to suppress crime statistics (Rayman, 2011; Eterno and Silverman, 2012), monetary damage settlements of more than $\$ 57$ million per year over the past decade in police misconduct litigation (Hennelley, 2010), allegations of arrest and "stop" quotas and illegal arrests (Powell, 2012), extensive targeted surveillance of Muslim groups in madrassas and mosques both inside the City and in neighboring cities (Associated Press, 2012), constitutional violations in the handling of political demonstrations in 2004 and in the current Occupy Wall Street movement, and chronic conflicts with the press over reporting of crime and political demonstrations. Even as crime rates decline in a period where the NYPD force has shrunk by over 6,000 officers (Zimring, 2011), the tension between ethnic minorities and the NYPD remains front-and-center.

While the LAPD has emerged from a period of crisis and deep institutional reform to build an umbrella of legitimacy through close ties to the varied communities of LA, the current posture of the NYPD and the resistance to 
outside monitoring and internal reforms suggests a less clear future. The LAPD has harmonized, to the extent possible given its recent past, with the future of the social fabric of LA. The same cannot be said in NYC. Many citizens in NYC, including those most heavily policed, await the next mayor and police commissioner to see whether a new era of reform can begin that includes citizen trust and satisfaction as an outcome equally worthy of addressing as the crime rate.

\section{References}

Abu-Lughod, Janet L. 2007. Race, Space, and Riots in Chicago, New York, and Los Angeles. New York: Oxford University Press.Alpert, G., et al. (2006). Analysis Group, Inc., Pedestrian And Motor Vehicle Post-Stop Data Analysis Report.

Ash, Timothy Garton (ed.) (1999), History of the Present: Essays, Sketches and Dispatches from Europe in the 1990s. New York: Random House

Ayres, Ian, and Jonathan Borowsky. 2008. Racial Profiling \& The LAPD: A Study of Racially Disparate Outcomes in the Los Angeles Police Department. Los Angeles: American Civil Liberties Union of Southern California, available at: http://www.aclu-sc.org/documents/view/47

Berk, Richard A., and John MacDonald. 2010. "Policing the Homeless: An Evaluation of Efforts to Reduce Homeless-Related Crime." Criminology and Public Policy, 9(4): 813-840.

Blasi, Gary. 2007. Policing Our Way Out of Homelessness?: The First Year of the Safer Cities Initiative on Skid Row (NCJ 237249). Washington DC: U.S. Department of Justice. Available at: http://lacatholicworker.org/agitator/blasi_study.pdf

Blumstein, Alfred J. 1995. "Youth Violence, Guns, and the Illicit-Drug Industry." Journal of Criminal Law \& Criminology 86: 10-36 (1995-1996) Blumstein, Alfred

Blumstein, Alfred J., and Joel Wallman (eds.). 2000. The Crime Drop in America. New York: Cambridge University Press.

Bowles, Samuel, Steve Durlauf, and Karla Hoff (eds.). 2006. Poverty Traps. Princeton, N.J.: Princeton University Press

Bratton, William and Peter Knobler (1998). The Turnaround: How America's Top Cop Reversed the Crime Epidemic . New York: Random House.

Cohen, Jerry, and William S. Murphy. 1966. Burn, Baby, Burn!: The Los Angeles Race Riot, August 1965. New York: E.P. Dutton

Commission to Investigate Alleged Police Corruption. 1973. Report of the Commission to Investigate Alleged Police Corruption. New York: Braziller Press. Also known as The Knapp Commission Report. 
Cook, Philip J., and John H. Laub (1998). "The Unprecedented Epidemic of Youth Violence.” Crime And Justice: A Review of Research, 24: 27-64.

Christopher Commission, 1998. Final Report, www.hrw.org 1998 Reports

Cutler, David M., Edward L. Glaeser, and Jacob L. Vigdor. 1999. "The Rise and Decline of the American Ghetto." Journal of Political Economy 107:455-506.

-----. 2008. "Is the Melting Pot Still Hot? Explaining the Resurgence of Immigrant Segregation." The Review of Economics and Statistics 90:478-97.

Davies, Garth, and Jeffrey Fagan, J. 2012. "Crime and Enforcement in Immigrant Neighborhoods: Evidence from New York City," Annals of the American Society of Political and Social Science 641: 99 -

Dickey, Christopher. 2009. Securing the City: Inside America's Best Counterterror Force. New York: Simon and Schuster.

English, T.J. 2011. The Savage City: Race, Murder and a Generation on the Edge. New York: William Morrow

Eterno, John A., and Eli B. Silverman, 2011. The Crime Numbers Game: Management by Manipulation. New York: CRC Press.

Fagan, J.A. "Intoxication and aggression." Drugs and Crime -- Crime and Justice: An Annual Review of Research 13: 241-320, 1990.

Fagan, Jeffrey A. "Do Criminal Sanctions Deter Drug Offenders? Pp. 188-214 in Drugs and Criminal Justice: Evaluating Public Policy Initiatives, edited by Doris MacKenzie and Craig Uchida. Newbury Park, CA: Sage Publications, 1994.

Fagan, Jeffrey A. "The Political Economy of Drug Dealing among Urban Gangs." Pp. 19-54 in Drugs and Community, edited by Robert Davis, Arthur Lurigio and Dennis P. Rosenbaum. Springfield, IL: Charles Thomas, 1993.

Fagan, Jeffrey A. "Drug selling and licit income in distressed neighborhoods: The economic lives of street-level drug users and dealers." Pp. 99-142 in Drugs, Crime and Social Isolation: Barriers to Urban Opportunity, edited by George E. Peterson \& Adelle V. Harrell. Washington DC: Urban Institute Press, 1992.

Fagan, Jeffrey, and Garth Davies. 2007. Immigration, Neighborhood Selection and Crime in New York City: Race- and Ethnicity-Specific Effects. Presented at the Annual Meeting of the American Society of Criminology, Los Angeles, November.

Fagan, Jeffrey, Amanda Geller, Garth Davies and Valerie West. 2010. "Street Stops and Broken Windows Revisited: Race and Order Maintenance Policing in a Safe and Changing City" in Exploring Race, Ethnicity and Policing: Essential Readings (S. Rice and M. White, eds.), New York University Press 309-

Fagan, Jeffrey, Franklin E. Zimring, and June Kim. 1998. "Declining Homicide in New York: A Tale of Two Trends." Journal of Criminal Law and Criminology 88: 1277-1324, 1998. 
Fagan, Jeffrey, and Garth Davies. 2000. "Street Stops and Broken Windows: Terry, Race and Disorder in New York City," Fordham Urban Law Journal 28: 457-504

Fagan, Jeffrey, and Tracey L. Meares. 2008. "Punishment, Deterrence and Social Control: The Paradox of Punishment in Minority Communities." 6 Ohio State Journal of Criminal Law 6: 173-229 (2008).

Feagin, Joe R., and Paul B. Sheatsley (1968). Ghetto Resident Appraisals of a Riot, Public Opinion Quarterly 32:352

Garland, David. 2001 Culture of Control: Crime and Social Order in Contemporary Society Chicago: University of Chicago Press.

Gascón, George. 2005. "CompStat Plus: In-Depth Auditing, Mentorship, Close Collaboration." The Police Chief 72 (May 2005): 34-43.

Gelman, Andrew, Jeffrey Fagan, and Alex Kiss. 2007. "An Analysis of the NYPD's Stop-and-Frisk Policy in the Context of Claims of Racial Bias," Journal of the American Statistical Association 102: 813-823

Glaeser, Edward, Triumph of the City. New York: Penguin Books

Glenn, Russell W., Barbara Raymond, Dionne Barnes-Proby, Elizabeth Williams, John Christian, Matthew W. Lewis, Scott Gerwehr and David Brannan. 2003. Training the 21st Century Police Officer: Redefining Police Professionalism for the Los Angeles Police Department. Report No. MR1745. Santa Monica, CA: RAND Corporation, 2003.

Goldstein, Paul J. 1985. "The Drugs/Violence Nexus: A Tripartite Conceptual Framework. Journal of Drug Issues, 15(4):493-506.

Goldstein, Paul J, Henry H. Brownstein, Patrick Ryan, \& Pam Bellucci. 1989. Crack and homicide in New York City, 1988: A Conceptually Based Event Analysis. Contemporary Drug Problems 16: 651-687.

Greene, Jack R. 1998. The road to community policing in Los Angeles: A case study. In Community policing: Contemporary readings, edited by G. Alpert and A. Piquero. Prospect Heights, Illinois: Waveland Press.

Harcourt, Bernard E. 2001. Illusion of Order: The False Promise of Broken Windows Policing. Cambridge MA: Harvard University Press.

Harcourt, Bernard E. 2005. Policing L.A.'s Skid Row: Crime and Real Estate Development in Downtown Los Angeles (An Experiment in Real Time). University of Chicago Legal Forum, Volume 2005.

Harcourt, Bernard E. and Jens Ludwig. 2006. "Broken Windows: New Evidence from New York City and a Five-City Social Experiment." The University of Chicago Law Review 73(1): 271-320.

Hemenway, David. 2004. Private Guns, Public Health. Ann Arbor MI: University of Michigan Press.

Hennelley, Robert. 2012. Amid Budget Wrangling, Council Takes Aim at Soaring NYPD Payouts.” WNYC News, May 20, 2012. Available at: http://www.wnyc.org/articles/wnyc-news/2012/may/20/nypd-tort/

Herbert, Bob. 1998a. "Day of Humiliation," New York Times, March 8, 1998. 
Herbert, Bob. 1998b. "A Cop's View," New York Times, March 15, 1998.

Human Rights Watch. 1998. Shielded from Justice: Police Brutality and Accountability in the United States. New York: Human Rights Watch. Available at: http://www.hrw.org/legacy/reports98/police/index.htm

Independent Commission on the Los Angeles Police Department. 1991. Report of the Independent Commission on the Los Angeles Police Department.

Available at: http://www.parc.info/client_files/Special\%20Reports/1\%20\%20Chistopher $\% 2$ 0Commision.pdf

Jeffries, Eric, Robert Kaminski, Steven Holmes, and Dana Hanley. (1997). "The Effect of a Videotaped Arrest on Public Perceptions of Police Use of Force." Journal of Criminal Justice 25: 381-395.

Johnson, Bruce D., Terry Williams, Kojo A. Dei and Harry Sanabria. 1990. "Drug Abuse in the Inner City: Impact on Hard-Drug Users and the Community." Crime and Justice (Drugs and Crime) 13: 9-67

Karmen, Andrew. 2000. New York Murder Mystery. The True Story behind the Crime Crash of the 1990s. New York: New York University Press.

Kelling, George and Catherine Cole. 1996. Fixing Broken Windows, New York: Free Press.

Kraus, Clifford. 1995. "Bratton Assailed on Ouster of Top Official," New York Times, January 29, 1995.

LaFave, Wayne R. (1965). Arrest: The Decision to Take a Suspect into Custody. American Bar Foundation.

Letwin, Michael. 1990. "Report from the Front Line: The Bennett Plan, StreetLevel Drug Enforcement in New York City, and the Legalization Debate." Hofstra Law Review 18: 795

Lim, Nelson, Carl Matthies, Greg Ridgeway, and Brian Gifford. 2009. To Protect and to Serve: Enhancing the Efficiency of LAPD Recruiting, Report No. MG-881-RMPF. Santa Monica, CA: RAND Corporation.

Liu, John C. 2012. Comprehensive Annual Report of the Comptroller for the Fiscal Year Ended June 30, 2011. New York: Office of the Comptroller of the City of New York. http://www.comptroller.nyc.gov/bureaus/acc/cafrpdf/CAFR2011.pdf

Maple, Jack and Christopher Mitchell (1999) The Crime Fighter: Putting the Bad Guys Out of Business. New York: Broadway Books.

MacDonald, John M., John Hipp, and Charlotte Gill. 2012. The Effects of Immigrant Concentration on Changes in Neighborhood Crime Rates? Journal of Quantitative Criminology. Online first (June 2, 2012) DOI 10.1007/s10940012-9176-8

Malone N, Baluja KF, Costanzo JM, Davis CJ (2003) The foreign-born population: 2000. Census 2000 brief. U.S. Census Bureau, Washington DC. Retrieved August 11, 2009 (http://www.census.gov/prod/2003pubs/c2kbr34.pdf) 
Maple, Jack and Christopher Mitchell (1999) The Crime Fighter: Putting the Bad Guys Out of Business. New York: Broadway Books.

Martinez R Jr, Stowell JI, Lee MT (2010) Immigration and crime in era of transformation: a longitudinal analysis of homicides in San Diego neighborhoods, 1980-2000. Criminology 48:797-830

Massey, Douglas S., and Nancy Denton. (1993), American Apartheid: Segregation and the Making of the Underclass, Cambridge, MA: Harvard University Press.

Mastrofski, Stephen D., R.R. Ritti, and Jeffrey B. Snipes (1994). "Expectancy Theory and Police Productivity in DUI Enforcement," Law and Society Review 28:113-148.

McDonald, Phyllis. 2000. "Cop, COMPSTAT, and the New Professionalism: Mutual Support or Counter Productivity.” In Alpert, Geoffrey and Roger Dunham (eds.) Critical Issues in Policing: Contemporary Readings. Prospect Heights: IL: Waveland Press.

McCone Commission. 1965. Violence in the City: An End or a Beginning? Final Report of the Governor's Commission on the Los Angeles Riots. Available at: http://www.usc.edu/libraries/archives/cityinstress/mccone/contents.html

Mollen, Milton (Chair). 1994. Anatomy of Failure: Path to Success. Report of the City of New York Commission to Investigate Allegations of Police Corruption and the Anti-Corruption Procedures of the Police Department. New York: Commission to Combat Police Corruption. Available at: http://www.parc.info/client_files/Special\%20Reports/4\%20\%20Mollen $\% 20 \mathrm{C}$ ommission $\% 20-\% 20$ NYPD.pdf

Moore, Mark H. 2002. Recognizing Value in Policing. Washington DC: Police Executive Research Forum

Morenoff Jeffrey D., and A. Astor A. 2006. Immigrant Assimilation and Crime: Generational Differences in Youth Violence in Chicago. In: Martinez R Jr, Valenzuela A Jr (eds) Immigration and crime: race, ethnicity and violence. New York University Press, New York, pp 36-63.

Morenoff Jeffrey D., and Robert J. Sampson. 1997. "Violent Crime And The Spatial Dynamics Of Neighborhood Transition: Chicago, 1970-1990.” Social Forces 76(1):31-64

Morenoff Jeffrey D., Robert J. Sampson, and Steven W. Raudenbush. 2001. Neighborhood Inequality, Collective Efficacy, And The Spatial Dynamics Of Urban Violence. Criminology 39(3):517-558

Nagin, Daniel S. 2005. Group-based Modeling of Development. Cambridge, MA.: Harvard University Press.

Nagourney, Adam. 2011. In Los Angeles, A Police Department Transformed. New York Times, August 12, 2011, available at: http://www.nytimes.com/2011/08/13/us/13lapd.html?pagewanted=all

National Commission on the Causes and Prevention of Violence. 1969. To Establish Justice, to Insure Domestic Tranquility: The Final Report of the National Commission on the Causes and Prevention of Violence. 
Washington DC: U.S. Government Printing Office. Available at:

http://www.eisenhowerfoundation.org/docs/National\%20Violence $\% 20$ Commi ssion.pdf. Also known as The Eisenhower Commission Report.

National Advisory Commission on Civil Disorders. 1968. Report of the National Advisory Commission on Civil Disorders. Washington DC: U.S. Government Printing Office. Available at: www.eisenhowerfoundation.org/docs/kerner.pdf. Also known as The Kerner Commission Report.

National Commission on Law Observance and Enforcement. 1931. Proposals To Improve Enforcement Of Criminal Laws Of The United States. Washington DC: U.S. Department of Justice. Also known as The Wickersham Commission

New York Times. 1994. Editorial, Policing the Police. New York Times, May 1, 1994

Oberschall, Anthony. 1968. "The Los Angeles Riot of August 1965" Social Problems 15: 322-341.

Passel, Jeffrey, and Roberto Suro. 2005. Rise, Peak, and Decline: Trends In U.S. Immigration 1992-2004. PEW Hispanic Research Center. Available at http://www.wwww.pewcenteronthestates.org/uploadedFiles/wwwpewtrustsor $\mathrm{g} /$ Reports/Hispanics in America/PHC politics_0605.pdf

Perlstein, Rick. 2008. Nixonland: The Rise of a President and the Fracturing of America. New York: Simon and Schuster

Portes Alejandro, and Ruben Rumbaut. 1990. Immigrant America: a portrait. University of California Press, Berkeley Portes A, Zhou M (1993) The new second generation: segmented assimilation and its variants. Annals of the American Academy of Political and Social Sciences 530:74-96

Powell, Michael. 2012. No Room for Dissent in a Police Department Consumed by the Numbers. New York Times, May 7, 2012, p. A22.

Preble, Edward J., and John J. Casey. 1969. "Taking Care of Business: The Heroin User's Life on the Street." International Journal of the Addictions 4(1):1-24.

Rampart Independent Review Panel. 2000. Final Report of the Rampart Independent Review Panel. Available at: http://www.ci.la.ca.us/oig/rirprpt.pdf

Rampart Independent Review Panel. 2001. A Report To The Los Angeles Board Of Police Commissioners Concerning Special Order 40. Available at: http://www.lacity.org/oig/Special_Order_40_708061_v1.pdf

Rayman, Graham. 2012. The NYPD Tapes Confirmed. Village Voice, March 7, 2012, available at: http://www.villagevoice.com/2012-03-07/news/the-nypdtapes-confirmed/

Reckless, Walter C., and Mapheus Smith. 1932. Juvenile Delinquency. New York: McGraw Hill

Ridgeway, Greg (2007). Analysis of Racial Disparities in the New York Police Department's Stop, Question, and Frisk Practices. RAND Corporation, TR- 
534. Available at

http://www.rand.org/pubs/technical_reports/2007/RAND_TR534.pdf

Rosenfeld, Richard A., Robert Fornango, and Eric Baumer, E. 2005. "Did Ceasefire, Compstat, And Exile Reduce Homicide?” Criminology \& Public Policy 4: 419-449.

Sampson, Robert J. 2008. Rethinking Crime and Immigration. Contexts 7 (1): 2833.

Sampson, Robert J. and Jeffrey Morenoff. 2006. "Durable Inequality: Spatial Dynamics, Social Processes, and the Persistence of Poverty in Chicago Neighborhoods.” Pp. 176-203 In Poverty Traps, edited by Samuel Bowles, Steve Durlauf, and Karla Hoff. Princeton, N.J.: Princeton University Press.

Sampson, Robert J., Stephen W. Raudenbush, and Felton Earls. 1997.

"Neighborhoods and Violent Crime: A Multilevel Study of Collective Efficacy." Science 277:918-24.

Schwartz, Amy E., Scott Susin, and Ivan Voicu. 2003. "Has Falling Crime Driven New York City's Real Estate Boom?” Journal of Housing Research 14 (1): 101-135.

Schwartz, Joanna C. 2010. Myths and Mechanics of Deterrence: The Role of Lawsuits in Police Department Decision Making. 57 UCLA LAW REVIEW $1023-1094$

Sellin, Thorsten. 1938. Culture conflict and crime. American Journal of Sociology 44 (1): 97-103.

Shaw, Clifford R., and Henry D. McKay. 1942. Juvenile delinquency and urban areas. Chicago, IL: University of Chicago Press.

Skogan, Wesley G. 1990. Disorder and Decline. New York: Free Press

Skogan, Wesley G. 2006. Police and Community in Chicago: A Tale of Three Cities. New York: Oxford University Press.

Skogan, Wesley G., and Kathleen Frydl. 2004. Fairness and Effectiveness in Policing: The Evidence. Washington DC: National Academies Press.

Skogan, Wesley G. and Susan M. Hartnett. 1997. Community Policing, Chicago Style New York: Oxford University Press.

Smith, David J. 2008. The Foundations of Legitimacy, pp. 30-51 in LEGITIMACY And Criminal Justice in Comparative Perspective (T. Tyler et al., eds.) . New York: Russell Sage Foundation Press.

Smith, Dennis C., and Robert Purtell. 2007. “An Empirical Assessment of NYPD's 'Operation Impact': A Targeted Zone Crime Reduction Strategy." Unpublished, available at http://wagner.nyu.edu/news/impactzoning.doc

Spitzer, Elliott. (1999), “The New York City Police Department's 'Stop and Frisk' Practices," Office of the New York State Attorney General; available at http://www.oag.state.ny.us/bureaus/civil_rights/pdfs/stp_frsk.pdf

Stone, Christopher, Todd Fogelson and Christine M. Cole. 2009. Policing Los Angeles Under a Consent Decree: Dynamics of Change at the LAPD. Cambridge MA: Program in Criminal Justice, Harvard Kennedy School, 
Harvard University. Available at http://www.lapdonline.org/assets/pdf/Harvard-LAPD\%20Study.pdf

Stowell, Jacob. I., Steven F. Messner, Kelly Mcgeever, and L. E. Raffalovich. 2009. "Immigration and the Recent Violent Crime Drop in the United States: A Pooled, Cross-Sectional Time-Series Analysis f Metropolitan Areas." Criminology 47: 889-928.

Stuntz, Wiliam J. 2011. The Collapse of American Criminal Justice. Cambridge, MA: Harvard University Press.

Sutherland, Edward. 1934. Principles of Criminology (2nd. ed.). Philadelphia: J.B. Lippincott.

Toby, Jackson. 1957. "Social Disorganization and Stake in Conformity: Complementary Factors in the Predatory Behavior of Hoodlums." The Journal of Criminal Law, Criminology, and Police Science 48(1): 12-17

Tonry, Michael. 1997. Ethnicity, Crime, And Immigration. Crime and Justice 21:1-29.

Tuch, Stephen, and Ronald Weitzer. 1997. The Polls-Trends: Racial Differences In Attitudes Toward The Police. Public Opinion Quarterly 61: 642-663.

Tyler, Tom R. 1990. Why people obey the law. New Haven, CT: Yale Univ. Press.

Tyler, Tom R. 2010. Why People Cooperate: The Role of Social Motivations. Princeton NJ: Princeton University Press.

Tyler, Tom R., and Jeffrey Fagan. 2008. "Legitimacy, Compliance and Cooperation: Procedural Justice and Citizen Ties to the Law," Ohio State Journal of Criminal Law 6: 231-275

Van Ryzin, Greg and Andrew Genn. 1999. Neighborhood Change and the City of New York's Ten-Year Housing Plan, 10 Housing Policy Debate 799 (1999).

Walker, Anders. 2012. Theatres of Procedure. Available at SSRN: http://ssrn.com/abstract=1999471

Walker, Samuel. 1993. Taming the System: The Control of Discretion in Criminal Justice, 1950-1990. Oxford: Oxford University Press.

Weiner, Neil A., and Marvin E. Wolfgang. 1989. Neil Alan Weiner \& Marvin E. Wolfgang, Violent Crime in America, 1969-1982, in AMERICAN ViolenCE AND Public Policy,

Weitzer, Ronald. 2002. "Perceptions Of Racial Profiling: Race, Class, And Personal Experience." Journal of Criminal Justice 30 (5): 397-408

Weitzer, Ronald, and Tuch, Stephen A. 2006. Race And Policing In America: Conflict And Reform. New York: Cambridge University Press.

Weitzer, Ronald, Stephen A. Tuch, and Wesley G. Skogan. 2008. "PoliceCommunity Relations in a Majority Black City," Journal of Research in Crime \& Delinquency, 45: 398-428.

Wilson, James Q. 1968. Varieties of Police Behavior. Cambridge: Harvard University Press. 
Wilson, James Q. and George L. Kelling. 1982. Broken Windows: The Police and Neighborhood Safety. Atlantic Monthly, March, 29 - 38.

Zimring, Franklin E. 2011. The City That Became Safe. New York: Oxford University Press.

Zimring, Franklin E., and Gordon Hawkins. 1997. Crime is Not the Problem: Lethal Violence in America. New York: Oxford University Press.

\section{Cases Cited}

People v. Epton, 19 N.Y.2d 496 (1967)

Epton v. New York, 390 U.S. 976 (1968)

Epton v. New York, 398 U.S. 944 (1970)

Daniels et al. v. City of New York (2004), Stipulation of Settlement, 99 Civ 1695 (S.D.N.Y.) (SAS)

Terry $v$ Ohio, 392 U.S. 1 (1968)

Floyd et al. v. City of New York, 08 Civ. 1034 (S.D.N.Y.) (SAS)

Davis et al. v. City of New York, 10 Civ. 0699 (S.D.N.Y.) (SAS)

Ligon et al v. City of New York, (2012) 12 Civ. 2274 (SAS)

U.S. v. City Of Los Angeles, Civil No. 00-11769 (C.D. Cal.) (Gaf), Consent

Decree (2002) 


\section{Notes}

${ }^{1}$ The New York Post, as only the New York Post can, published a front page headline on September 7, 1990 that screamed "Crime-ravaged city cries out for help: Dave, Do Something." The headline was aimed at Mayor David Dinkins, demanding that he take strong measures to stop crime after a particularly gruesome few days of lethal violence in New York City. Dinkins did just that, collaborating with then-Speaker Peter Vallone of the New York City Council to pass the Safe Streets, Safe Cities Act in the state legislature, funding 5,000 new police officers who were deployed a year later in 1991. By 1992, crime had begun to fall, dropping 10 percent in two years (Fagan, Zimring and Kim, 1998; Karmen, 2000; Zimring, 2011). Crime has continued to fall for the next 20 years.

${ }^{2}$ Litigation in New York was filed by the Center for Constitutional Rights in 2001, following an investigation of the NYPD Stop and Frisk tactics by the New York State Attorney General (Spitzer, 1999). The 2001 litigation resulted in a Stipulated Settlement in Kelvin Daniels et al. $v$ City of New York et al, 99 Civ. 1695 (SAS). Subsequent litigation was filed by the Center for Constitutional Rights in January 2008 following the expiration of the Daniels settlement. The current case, David Floyd et al. v. City of New York et al. 08 Civ 1034 (SAS), will proceed to trial later this year. In Los Angeles, the United States Department of Justice (DOJ) filed a civil suit alleging that the Department was engaging in a pattern or practice of excessive force, false arrests and unreasonable searches and seizures. The litigation produced a Consent Decree in United States of America v. City of Los Angeles et al., that was signed in 2001.

${ }^{3}$ David Garland points out in Culture of Control (2001) that two entire generations of Americans and Britains have knowledge only of insecurity, and either lack knowledge of or can't remember low crime eras. This tends to make criminology a distinctly ahistorical discipline. Most active criminologists were born after 1960 and received their advanced degrees after 1980. As a cohort, they have no memory of low crime eras or the theory and discourse on crime in the lower crime eras that predate the Presidents Commission on Law Enforcement and Criminal Justice (1967) or the Kerner Commission Report (1968). There also are some difficulties in accessing reliable data on those eras. Current theory on crime is framed by the limitations of our data sources, which too often began after 1975 for crime victimization or 1968 for homicide.

${ }^{4}$ For illustrations of this Foucaultian idea, see David Garland (2001). See, also, Timothy Garton Ash (ed.) (1999).

${ }^{5}$ During the riot, the incomparable baseball pitcher Sandy Koufax pitched a no-hitter for the team, the Dodgers, in a game that was witnessed by fewer than one fifth of those who had bought tickets.

${ }^{6} \mathrm{http}: / /$ www.lapdonline.org/history_of_the_lapd/content_basic_view/1110

${ }^{7}$ Chief Parker died within a year of the Watts riots. He was replaced in by Ed Davis, who instituted several reforms that sought closer ties to the minority community. One innovation was the Basic Car Plan, which assigned officers to specific geographic boundaries, an early version of local - if not community - policing. Davis also increased the number of specialized units (Encyclopedia of Police Science). Aside from these marginal changes though, the LAPD remained focused on police efficiency and administration while rebuilding community relations damaged by the riots (Greene, 2007). Daryl Gates succeeded Parker in 1978, an internal hire. He focused primarily on budget-driven reductions in hiring during massive population growth, the emergence of 
dense networks of street gangs, and the first of two waves of rising crime rates. Gates served as LAPD chief of police until he retired under pressure in 1992 after the riots set off by the Rodney King incident.

${ }^{8}$ King had previously been convicted of driving while intoxicated and was currently driving under a suspended license. He led the LAPD on a high speed chase for approximately 10 minutes. In total 12 cars were involved in the pursuit. Upon exiting the car King allegedly refused to lie down, was shot with a Taser and then was repeatedly hit with batons and kicked while on the ground (Christopher Commission, 1991). This may have been a routine police-citizen use of force case had it not been captured on videotape from a nearby resident.

${ }^{9}$ A poll taken by the LA Times newspaper shortly after the incident found that $87 \%$ of African-American and $80 \%$ of Hispanic respondents thought that police brutality in the LAPD was common (Christopher Commission, 1991; p. 16). Tuch and Wetizer's (1997) examination of LA Times public opinion poll data over periods before and after highly publicized incidents of police brutality (e.g., January 3, 1979 shooting of Eulia Love; March 3, 1991 beating of Rodney King) found dramatic reductions in public approval of the LAPD among African American and Hispanic respondents. Studies in other cities also show that high-profile media cases of police abuse increase minority distrust of the police (Jefferies et al. 1997; Weitzer 2002). The trends of declining opinion appear to last in LA until 1995 (Tuch and Weitzer, 1997), years after the LAPD had instituted its first series of reforms.

${ }^{10}$ Williams' five year term effectively removed the life tenure status of the police chief and made the LAPD executive more accountable to the political constituents. Williams was known for his ability form tight bonds with the public in Philadelphia the wake of the reforms that occurred to rebuild citizen trust Philadelphia police under the Rizzo administration were involved in numerous high-profile use of deadly force events. However, Williams experience in the LAPD was short-lived, as his powers as a chief were circumscribed in many ways, including limiting his ability to bring in outside command staff. The LAPD did, however, under Chief William's direction form a strategic plan for change that fully embraced the goals of community policing as well as the mission.

${ }^{11}$ See http://www.lapdonline.org/search_results/content_basic_view/6528

${ }^{12}$ Tbe BOI noted numerous problems recruitment screening and supervision of CRASH officers in the field, and downplayed wider problems of routine illegality by CRASH officers.

${ }^{13}$ See timeline provided by PBS documentary film: http://www.pbs.org/wgbh/pages/frontline/shows/lapd/bare.html.

${ }^{14}$ For example, the Knapp Report identified two particular classes of corrupt police officer, which it called "Grass Eaters" and "Meat Eaters." Each was endemic to the culture of the department, and the sustaining norms were passed on from the older generations of police to the new recruits. The classification itself refers to petty corruption under peer pressure ("eating grass") and aggressive premeditated major corruption ("eating meat"). "Grass Eaters" were police officers who routinely took five, ten, twenty dollar payments from contractors, tow-truck operators, gamblers, and others working both inside and outside the law. "Grass eating" was a way of life for many cops, normalized in the police culture, and was considered part of the "pay" for being a cop. The Knapp Commission found that "grass eating" was used by police officers to prove 
their loyalty to the "brotherhood" of cops, and was essential to sustaining the police culture. "Meat Eaters" were officers who "spend a good deal of time aggressively looking for larger paydays," such as shaking down pimps and drug dealers for money. The Commission noted that these officers justified this extortion by marginalizing their victims were criminals and underserving of police protection.

${ }^{15}$ The Mollen Commission heard from officers who admitted pouring ammonia on the face of a detainee in a holding cell and from another who threw garbage and boiling water on someone hiding in a dumbwaiter shaft. Another officer allegedly doctored an "escape rope" used by drug dealers so they would plunge to the ground if they used it, and the same group also raided a brothel while in uniform, ordered the customers to leave, and terrorized and raped the women there

${ }^{16}$ CNN News (1999.) "30-year sentence for N.Y. policeman in torture of black man". CNN.com. Retrieved May 25, 2012.

${ }^{17}$ See background at: http://www.lapdonline.org/history_of_the_lapd/content_basic_view/1120

${ }^{18} \mathrm{http}$ ://policechiefmagazine.org/magazine/index.cfm?fuseaction=print display\&article i $\mathrm{d}=593$ \&issue_id $=52005$

${ }^{19} \mathrm{http}: / /$ www.lapdonline.org/lapd_command_staff/comm_bio_view/7579

${ }^{20} \mathrm{http} / / /$ articles.latimes.com/2009/jul/18/local/me-consent-decree18

${ }^{21}$ See, http://topics.nytimes.com/top/reference/timestopics/subjects/s/stop and frisk/index.html

${ }^{22}$ One of us (Fagan) was a consultant to the New York State Attorney General and assisted in the analysis that was published in the Spitzer (1999) report on racial disparities and Fourth Amendment concerns in the NYPD Stop and Frisk Program. This review focuses on the larger social and political contexts of policing in New York before and after that era.

${ }^{23}$ See, Ligon et al v. City of New York for a description of how Operation Clean Halls operates. According to data provided by the City of New York in the Davis litigation, police conduct approximately 25,000 "vertical patrols" each month where they patrol the halls and stairwells of these buildings as well as buildings in New York City Housing Authority developments.

${ }^{24}$ To control for the potential under reporting of robberies over time we adjust robbery rates by subtracting the ratio of robberies to homicides in each year. This in effect reduces the influence that changes in the reporting of robbery will have on the robbery rate. A big ratio will result in down-weighting the rate or robberies. The results we display with or without this adjustment have no material effect.

${ }^{25}$ Adjusting robbery rates for changes in reporting practices relative to homicide doesn't change the story of the 1990s.

${ }^{26}$ The statistical analysis was not the only component of Bratton's reforms. He developed new models of accountability for field commanders, also instituted new tactics including aggressive street stops as part of his response in crime "hot spots." See, for example, Maple and Mitchell, 2000; Dickey (2009).

${ }^{27}$ Chain stores (e.g., Gap, Levi Straus, Disney, Toys 'R Us), hotels (e.g., Marriott, W, Hilton, Crowne Plaza), and entertainment (e.g., ESPN Zone, MTV), all with nationwide identity, proliferate in Times Square today. 
${ }^{28}$ Incarceration rates in the upstate counties contiguous to New York City have risen sharply since 2000, in part because of the social shock to quiet and homogenously white upstate areas of newly transplanted former City residents._See, e.g., Carrie Johnson, As Gangs Move to Upstate New York, So Too Does Crime, National Public Radio, Morning Edition, March 14, 2009, available at http://www.npr.org/2012/03/14/148160372/asgangs-move-to-new-york-suburbs-so-does-crime

${ }^{29}$ Boundary maps for these neighborhoods of approximately 15,000 population are available at http://www.nyc.gov/html $/ \mathrm{dcp} / \mathrm{html} / \mathrm{bytes} / \mathrm{meta}$ nynta.shtml

${ }^{30}$ Measured by a standardized value of percentage of foreign born residents and percentage of Hispanic/Latino residents

${ }^{31}$ Immigrant enclaves were matched with other neighborhoods based on local poverty index, a measure of residential stability, the number of males under age 25, and the regional patterns of immigration in Los Angeles.

${ }^{32}$ FBI index offenses, which include murder, rape, robbery, assault, burglary, theftperson, theft-vehicle, kidnap, arson of a dwelling, and motor vehicle theft

33 See, Joel Rubin, U.S. Judge Ends Federal Oversight Of The LAPD, Los Angeles Times, July 18, 2009, available at http://articles.latimes.com/2009/jul/18/local/meconsent-decree18 